\title{
Column Chromatography for Terpenoids and Flavonoids
}

\author{
Gülçin Saltan Çitoğlu and Özlem Bahadır Acıkara \\ Ankara University, \\ Turkey
}

\section{Introduction}

Natural products have coming from various source materials including terrestrial plants, terrestrial microorganisms, marine organisms, terrestrial vertebrates and invertebrates have importance as they provide an amazing source of new drugs as well as new drug leads and new chemical entities for further drug development (McCurdy \& Scully, 2005; Chin et al., 2006). Morphine, vincristine, codeine, digitoxin, quinine, galantamine and taxol are just some of the typical examples of drugs that have been introduced from natural sources (Heinrich et al., 2004; Balunas \& Kinghorn, 2005).

Natural products can be mainly divided into three groups such as primary metabolites, secondary metabolites and high molecular weight polymeric materials (Hanson, 2003). Primary metabolites including nucleic acids, amino acids, sugars; occur in all cells and play a central role in the metabolism and reproduction of the cells. High molecular weight polymeric materials such as cellulose, lignins and proteins take a part in the cellular structure. Secondary metabolites, small molecules which are not essential for the growth and development of the producing organism have importance because of their biological activities on other organisms. Natural product term refers to any naturally occurring compounds but in most cases mean secondary metabolite (Hanson 2003; Sarker et al., 2005). Secondary metabolites mainly consist of these following groups:

- $\quad$ Terpenoids and steroids

- $\quad$ Fatty acid derivatives and polyketides

- $\quad$ Alkaloids

- Phenylpropanoids

- Nonribozomal polypeptides

- $\quad$ Enzyme cofactors (McMurry, 2010).

\section{Isolation of terpenoids and flavonoids by column chromatography}

\subsection{Terpenoids}

Terpenoids are the most widespread, chemically interesting groups of secondary metabolites with over 30,000 known compounds including steroids (Wang et al., 2005; Umlauf, 2004). Many terpenes have biological activities and are used for the treatment of 
human diseases. Among the pharmaceuticals, the anticancer drug Taxol® and the antimalarial drug Artimesinin are two of the most renowned terpene-based drugs. Terpenoids and steroids are originated from isoprenoit $\left(C_{5}\right)$ units derived from isopentenyl (3-methyl-3-en-1-yl) pyrophosphate. These $C_{5}$ units are linked together in a head-to-tail manner. Based on the number of the isoprene units, terpenoids are classified as monoterpenes $\left(C_{10}\right)$, sesquiterpenes $\left(C_{15}\right)$, diterpenes $\left(C_{20}\right)$, sesterpenes $\left(C_{25}\right)$, triterpenes $\left(C_{30}\right)$, tetraterpenes $\left(C_{40}\right)$ and polyterpenes (Wang et al., 2005). Mono and sesquiterpenes are the main constituents of the essential oils. However di- and triterpenoids which are not volatile compounds, generally found in gums and resins. Tetraterpenoids constitute a group of terpenoids called as carotenoids. This group includes carotenes, xanthophylls and carotenoic acids and the most important polyterpenoid is the rubber (Sameeno, 2007; Raaman, 2006).

Terpenoids are chemically lipid-soluble compounds and they can be extracted with petroleum ether generally. Sesquiterpene lactones, diterpenes, sterols and less polar triterpenoids extraction can be also performed by using benzene, ether and chloroform. Ethyl acetate and acetone extracts contain oxygenated diterpenoids, sterols and triterpenoids. Ethanol, methanol and water led to the extraction of highly oxygenated namely polar triterpenes as well as triterpenoid and sterol glycosides. Total extraction of the material carried out by any polar solvents such as acetone, aqueous methanol (\%80) and aqueous ethanol and then re-extraction with hexane, chloroform and ethyl acetate is also leads to successive extraction of terpenoids and sterols (Harborne, 1998; Bhat, 2005).

Gas-Liquid Chromatography (GLC) is known as the best method for analyses of terpenoids especially mono- and sesquiterpenoids. Isolation of the mono- and sesquiterpenoids is also achieved by preparative GLC currently. Thin layer chromatography (TLC) can be used as another rapid, useful method for terpenoids and sterols detection with concentrated $\mathrm{H}_{2} \mathrm{SO}_{4}$ and heating due to all terpenoids and steroids (except carotenoids) are colourless compounds. TLC is also allowing to the isolation of various classes of terpenoids on silica gel and silver nitrate impregnated silica gel coated plates (Harborne, 1998; Bhat, 2005).

For isolation of various terpenoids especially sesqui-, di-, tri- and tetraterpenoids as well as sterols column chromatography is convenient method. As stationary phase silica gel, alumina, cellulose, sephadex, polyamid are used for the separation of different types of secondary metabolites but of this silica gel is the most extensively used adsorbent for particularly nonpolar and medium polar compounds including terpenoids and sterols. Silver nitrate impregnated silica gel is also provide separation of terpenoids containing unsaturation (Bhat, 2005; Sarker et al., 2006). Terpenoids are generally alicyclic compounds and isomerism is common. Due to the twisted cyclohexane ring, in chair form, different geometric conformations are possible depending on the substitution around the ring. Therefore, stereochemistry is commonly found in terpenoids. These structural features may cause artifact formation during isolation procedure (Harborne, 1998).

\subsubsection{Monoterpenoids}

The monoterpenoids which are composed of the condensation of two isoprene units are important components of essential oils (Gould, 1997). They are widely distributed in nature, most of which have been found in higher plants. However a number of halogenated 
derivatives have been isolated from marine organisms and have been found in defense and pheromonal secretions of insects. Monoterpenes have intensely purgent odors and they are the most common volatile compounds in plants responsible for fragrance and flavor. Therefore monoterpenes have a great commercial interest for food industry as well as perfume and fragrance industry (Robbers et al., 1996). Geraniol, a major component of geranium oil (Pelargunium graveolens) and its isomer, linalool; citral a major constituent of lemon oil, is obtained commercially from lemon grass oil (Cymbopogon flexuosus), menthol is found in the essential oil of the field mint, Mentha arvensis, and possesses useful physiological properties including local anaesthetic and refreshing effects, terpineol and a-pinene are found in pine oil (turpentine), camphor, which was isolated from the camphor tree, Cinnamomum camphora are some of the typical examples of monoterpenoids (Hanson, 2003).

Isolation for mono- as well as sesquiterpenoids the classic procedure is obtaining essential oils by steam distillation. However extraction with non-polar solvents such as petroleum ether, ether and hexane can be preferred due to artifact formation at the raised temperatures (Harborne, 1998). Adsorbtion chromatography on silica gel is the simplest and most effective method for separation of terpenoids and GLC is used commonly for identification as well as isolation of the monoterpenoids. Column chromatography is also a valid method for fractionation of monoterpenoids. Isocratic elutions with solvents such as pentane, petroleum ether, hexane or gradient elution with mixtures of solvents in increasing polarity leads to successive isolation (Sur, 1991). Additionally, faster techniques of column chromatography such as flash chromatography may be preferred due to conventional column chromatography for separating procedure is time-consuming and frequently gives poor recovery owing to band tailing (Ikan, 1991).

The genus Tagetes belongs to the Asteraceae family. Tagetes minuta has essential oil and ocimenone which was reported to have mosquito larvicidal activity is the major constituent of this oil. Separation of the essential oil of T. minuta on silica gel column eluting with $\mathrm{Et}_{2} \mathrm{O}$ resulted in 10 fractions which the first four of these led to the isolation of $(Z)$ - $\beta$-ocimene, dihydrotagetone, (Z)-tagetone (Z)-ocimenone and (E)-ocimenone. Additionally, 3,7dimethyloct-1-en-6-one, 3,7-dimethyl-5-hydroxyoct-1-en-6-one and 3,7-dimethyloct-1,7dien-6-one were obtained by rechromatography of fraction V respectively (Garg \& Mehta, 1998). Tagetes patula L. another species from this genus allows to the isolation of acyclic monoterpene glycosides. Methanolic extract of the flowers was separated on silica gel column chromatography using $\mathrm{CHCl}_{3}-\mathrm{MeOH}$ mixtures to yield 2-methyl-6-methylen-2,7octadiene 1-O- $\beta$-D-glucopyranoside (Garg et al., 1999).

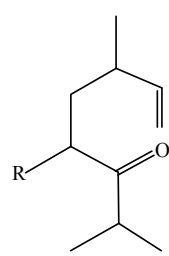

$\mathrm{R}=\mathrm{H} \quad 3,7$-dimethyloct-1-en-6-one

$\mathrm{R}=\mathrm{OH} \quad$ 3,7-dimethyl-5-hydroxyoct-1-en-6-one $\mathrm{R}=\mathrm{H}, \Delta^{7} \quad 3,7$-dimethyloct-1,7-dien-6-one

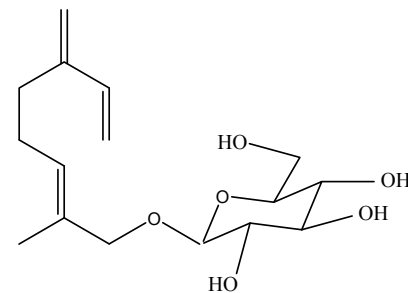

2-methyl-6-methylen-2,7-octadiene 1-O- $\beta$-Dglucopyranoside 
Artemisia tridentata ssp. vaseyana, Artemisia cana ssp. viscidula and Artemisia tridentata ssp. spiciform led to the isolation of monoterpenoids. For each plant sample, air-dried ground leaves and flower heads were extracted with pentane in soxlet extractor. The extracts were concentrated in vacuo, and vacuum short path distilled to yield yellowish oils. The each oil isolated from A. tridentata ssp. vaseyana, A. cana ssp. viscidula and A. tridentata ssp. spiciformis was separated by flash chromatography on silica gel using 19:1 hexane-EtOAc followed by 4:1 hexane-EtOAc except for the oil isolated from A. tridentata ssp. spiciformis which was flash chromatographed with 9:1 hexane-EtOAc as the second solvent system. A. tridentata ssp. vaseyana essential oil was separated into three major fractions by column chromatography. GC analysis of the first chromatographic fraction indicated the presence of four constituents. Two major compounds were isolated and identified by comparison of spectral data to literature values. The first was 1,8 cineole (eucalyptol) and the second was trans-3-(1-oxo-2-methyl-2-propenyl)-2,2-dimethylcyclopropylmethanol which is thermally unstable and isolated as its GC artifact 2,4-diisopropenyl-5 $\mathrm{H}$-furan. The third compound was 2,2-dimethyl-6-isopropenyl-2H-pyran and the fourth was 2,3-dimethyl-6-isopropyl-4Hpyran. Thujone was determined as the major components of the second fraction. In the third fraction sabinol, chrysanthemol, chrysanthemyl acetate, fraganyl acetate, fraganol and 2isopropenyl-5-methylhexa-trans-3,5-diene-1-ol were identified as the major components. Four major constituents obtained from Artemisia cana ssp. viscidula chromatographic separation and the compounds were identified as santolina triene, a-pinene, rothrockene and artemisia trien was found to be in first fraction. The second of four chromatographic fractions gave five components; artemiseole, 1-8 cineole, trans-3-(1-pylmethanol) which is thermally unstable and isolated as its GC artifact 2,4-diisopropenyl-5H-furan, 2,2-dimethyl-6isopropenyl-2H-pyran, 2-isopropenyl-5-methylhexa-trans-3,5-diene-1-ol. Crysanthemal as well as eight compounds identified as camphor, isolyratol, lyratol, chrysanthemol, chrysanthemyl acetate, fraganyl acetate, fraganol and 2-isopropenyl-5-methylhexa-trans-3,5-dien-1-ol eight compounds were isolated by preparative GC from the third and fourth chromatographic fraction of A. cana ssp. viscidula respectively. Volatile oils obtained from the neutral pentane extract of $A$. tridentata ssp. spiciformis were flash chromatographed into five separate fractions to give mainly known compounds. The first fraction containing hydrocarbons was analyzed by preparative GC and contained santolina triene, a-pinene, camphene and rothrockene. Fraction two contained artemiseole, 1,8-cineole and oxidosantolina triene, fraction three contained lyratal, thujone and camphor and fraction four contained sabinyl acetate and chrysanthemyl acetate. The final alcohol fraction contained a-santolina alcohol, sabinol, chrysanthemol, isolyratol, lyratol and lavandulol (Gunawardena et al., 2002).

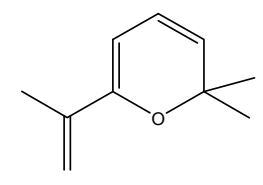

2,2-dimethyl-6-isopropenyl-2Hpyran

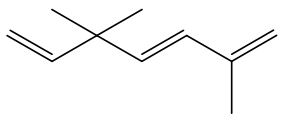

artemisia triene

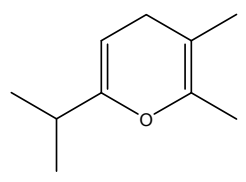

2,3-dimethyl-6-isopropyl-4Hpyran

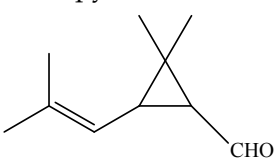

chrysanthemal

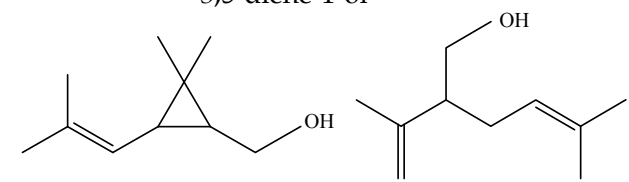

chrysanthemol

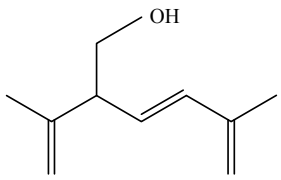

2-isopropenyl-5-methylhexa-trans3,5-diene-1-ol 


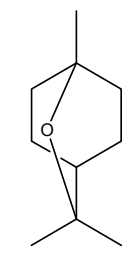

1,8-cineole

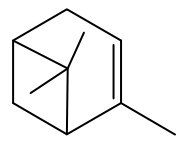

a-pinene
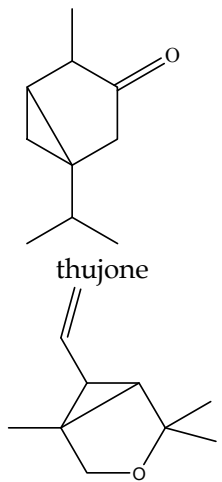

artemiseole

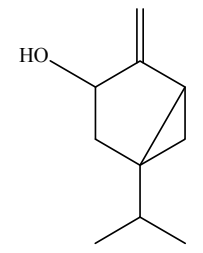

sabinol

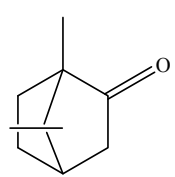

camphor<smiles>C=CC(C)(C=C(C)C)C(=C)C</smiles>

santoline triene<smiles>C=C1C2CCC(C2)C1(C)C</smiles>

camphene

Artemisia annua L. (sweet wormwood; Compositae), the source of the potent anti-malarial drug artemisinin, has been the subject of extensive phytochemical investigations over the past two decades. Sesquiterpenoids are the most abundant compounds in this species. Additionally, monoterpenoids, diterpenoids and flavonoids have been isolated. The seeds of A. annua were frozen in liquid $\mathrm{N}_{2}$ and converted into a powder by grinding with a pestle and mortar. The powder was repetitively extracted with $\mathrm{CH}_{2} \mathrm{Cl}_{2}$, dried $\left(\mathrm{MgSO}_{4}\right)$ and solvent removed under reduced pressure to yield an aromatic green gum which was subjected to gradient (hexaneEtOAc 5 to $100 \%$ ) column chromatography yielding 32 crude fractions. The crude fractions from column chromatography were further purified by repeated prep HPLC, using $n$-hexaneEtOAc-HOAc in varying proportions, according to the polarity of the crude fraction which was under investigation. Three monoterpenoids which was identified as 4-hydroxy-2isopropenyl-5-methylene-hexan-1-ol, 1,10-oxy-a-myrcene hydroxide and 1,10-oxy- $\beta$-myrcene hydroxide, was isolated together with sesquiterpenoids and diterpenoid (Brown et al., 2003).<smiles>C=C(C)C(O)CC(CO)C(=C)C</smiles>

4-hydroxy-2-isopropenyl 5-methylene-hexan-1-ol<smiles>C=C(C)C(O)CCC1=CCOC1</smiles>

1,10-oxy-a-myrcene hydroxide<smiles>CC(C)(O)/C=C/CC1=CCOC1</smiles>

1,10-oxy- $\beta$-myrcene hydroxide

Artemisia judaica (L.) is a perennial fragrant shrub which grows widely in the deserts and Sinai Peninsula of Egypt. Mixture of the dry leaves of A. judaica, A. monosperma and A. hera $a l b a$ is very common anthelmintic drug in the most of North African and Middle East countries under Arabic name of Shih. It has been reported that A. judaica essential oil has two major constituents as piperitone and trans-ethyl cinnamate. Piperitone showed insecticidal activity against Callosobruchus maculatus. Piperitone was isolated from aerial parts of the plant. Dried and powdered aerial parts of A. judaica were hydrodistilled in a Clevenger-type apparatus. The essential oil, pale yellow, was obtained and was dried over anhydrous sodium sulphate. The essential oil was chromatographed on silica gel column using hexane, $2.5 \%$ acetone-hexane, $10 \%$ acetone-hexane and acetone solvent system to give 45 fractions of $200 \mathrm{ml}$ of each. The resulting fractions were concentrated under reduced pressure and examined by TLC to offer two main fractions. Fractions 10-17 was subjected to silica gel column eluted with chloroform to offer of piperitone (Abdelgaleil et al., 2008). 


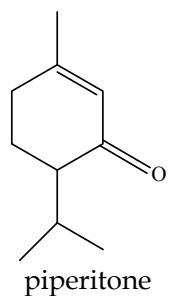

a-Pinene type monoterpenoids have been isolated from the aerial parts of Artemisia suksdorfii. Extraction was performed by using $\mathrm{CH}_{2} \mathrm{Cl}_{2}$ at room temperature and after concentrated, subjected to column chromatography on silica gel. Gradient mixtures of hexane and $\mathrm{CH}_{2} \mathrm{Cl}_{2}$ and then $\mathrm{CH}_{2} \mathrm{Cl}_{2}$ and methanol were used for elution to obtain five fractions. Fraction 3 and 4 were separated on silica gel column and eluted with n-hexane$\mathrm{CH}_{2} \mathrm{Cl}_{2}$ to yield Fraction 1-A and 1-B. Further purification with elution by using hexane: $\mathrm{CH}_{2} \mathrm{Cl}_{2}-\mathrm{MeOH}$ (5:7:0.5) of fraction 1-A on sephadex LH-20 column resulted in isolation of two a-pinene-type monoterpenoids; 7-hydroxymyrtenol and 7-hydroxymyrtenal (Mahmoud \& Ahmed, 2006).
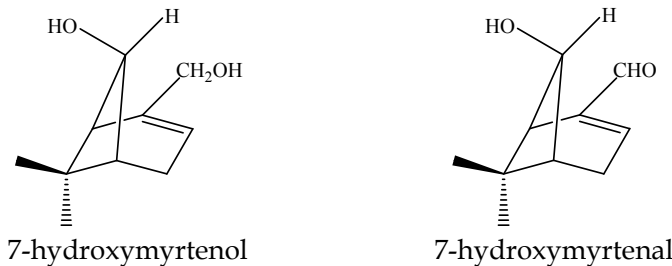

The Mentha genus (Labiatae) has importance as sources of essential oil production in the world. Additionally some members of this genus are used as herbal teas and spices. Menthone, mentol, menthyl acetate, neo-isomenthyl acetate, 1-menthyl- $\beta$-D-glucopyranosyl, 1-menthyl-6'-O-acetyl- $\beta$-D-glucopyranosyl have been identified mainly in various species. Mentha longifolia is widely distributed in Eurasia and tropical Asia. Longifone, a new chloro derivative of menthone was isolated from the aerial parts of the M. longifolia. After concentrated to dryness methanolic extract was re-diluted in water and then extracted with EtOAc. EtOAc soluble part subjected to silica gel column chromatography using hexane, hexane- $\mathrm{CHCl}_{3}, \mathrm{CHCl}_{3}$ and $\mathrm{CHCl}_{3}-\mathrm{MeOH}$ as mobile phase. Fraction that eluted with $20 \%$ $\mathrm{CHCl}_{3}$ in hexane yielded with longifone (M.S.Ali et al., 2002).<smiles>CC(C)C1CCC(C)(O)C(Cl)C1=O</smiles>

Passiflora quadrangularis L. (badea) is widely distributed in some regions of tropical America. Fruits of the plant are used locally to prepare different kinds of drinks with a pleasant and refreshing aroma. Two oxygenated monoterpenoids were isolated from the fruits extract whose odour strongly resembled the aroma of fresh fruit. After fruits were blended, 
pentane- $\mathrm{CH}_{2} \mathrm{Cl}_{2}$ (1:1) was used for extraction. Obtained organic extract was dried over $\mathrm{Na}_{2} \mathrm{SO}_{4}$ and concentrated. The concentrated extract was subjected to silica gel column chromatography with the following eluant solutions; pentane- $\mathrm{Et}_{2} \mathrm{O}$ (9:1), pentane- $\mathrm{Et}_{2} \mathrm{O}$ (2:1), pentane- $\mathrm{Et}_{2} \mathrm{O}(1: 1)$, pentane- $\mathrm{Et}_{2} \mathrm{O}(1: 2)$ and $\mathrm{Et}_{2} \mathrm{O}$ to obtain five fractions, fraction $\mathrm{I}$ to $\mathrm{V}$, respectively. Fraction III and fraction $\mathrm{V}$ were further fractionated by column chromatography over silica gel using hexane-AcOEt $(7: 1$ - 4:1) as eluents to yield (2E)-2,6-dimethyl-2,5heptadienoic acid and (3S)-(5E)-2,6-dimethyl-5,7-octadiene-2,3-diol respectively. To obtain glycoside of (2E)-2,6-dimethyl-2,5-heptadienoic acid and (3E)-3,7-dimethyl-3-octene-1,2,6,7tetrol fruits pulp was blended in a mixer with the $\mathrm{pH}$ adjusted to 7.0 with $5 \mathrm{~N} \mathrm{NaOH}$. After centrifugation supernatant was subjected to XAD-2 column chromatography and eluted with water then $\mathrm{MeOH}$. The $\mathrm{MeOH}$ eluate was fractioned by multilayer coil counter current chromatography using $\mathrm{CHCl}_{3}-\mathrm{MeOH}-\mathrm{H}_{2} \mathrm{O}$ (7:13:18) to yield fifty fractions. Fractions 20-30 were rechromatographed on silica gel column chromatography using $\mathrm{CHCl}_{3}-\mathrm{MeOH}(7: 1,5: 1$, 4:1, 3:1) mixtures. Fractions eluted with $\mathrm{CHCl}_{3}-\mathrm{MeOH}$ (7:1) gave (2E)-2,6-dimethyl-2,5heptadienoic acid- $\beta$-D-glucopyranosyl ester. (3E)-3,7-dimethyl-3-octene-1,2,6,7-tetrol was obtained from fractions eluted with $\mathrm{CHCl}_{3}-\mathrm{MeOH}$ (5:1) after column chromatography on silica gel using EtOAc-BuOH-H${ }_{2} \mathrm{O}$ (8:2:5) (Osorio et al., 2000).

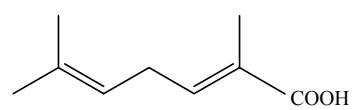

(2E)-2,6-dimethyl-2,5-heptadienoic acid<smiles>C=C/C(C)=C/CC(C)(C)O</smiles>

(3S)-(5E)-2,6-dimethyl-5,7-octadiene-2,3-diol

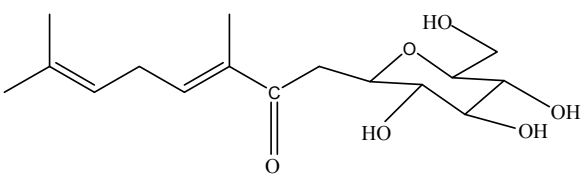

(2E)-2,6-dimethyl-2,5-heptadienoic acid $\beta$-Dglucopyranosyl ester<smiles>CC(=CCC(O)C(C)(C)O)C(O)CO</smiles>

(3E)-3,7-dimethyl-3-octene-1,2,6,7-tetrol

Alpinia kadsumadai Hayata is native to Hainan Island in Southern to China and has traditional usage in Chinese medicine as an antiemetic and for treatment of stomach disorders. Aerial parts of the A. kadsumadai contain monoterpenoids, sesquiterpenoids, diarylheptanoids, chalcones and flavonoids. $\mathrm{CH}_{2} \mathrm{Cl}_{2}$ extract of the aerial parts were subjected to column chromatography on silica gel and eluted with hexane-EtOAc mixture in increasing polarity. Fractions eluted with 15\% EtOAc-hexane gives 1-terpinen-4-ol (Ngo \&Brown, 1998).<smiles>CC1=CCC(O)(C(C)[AlH2])CC1</smiles>

Carum carvi L., Caraway (Umbelliferae) has been used as a popular aromatic herb and spice since antiquity and has been cultivated in Europe since the Middle Ages. Its fruit has been 
used for medicine and in cooking, and is listed in British, German and European pharmacopoeia. For medicinal purpose, it is used to relieve flatulent indigestion, colic and bronchitis. Studies on the fruits have revealed that the essential oil, and many monoterpenoids (d-carvone (main; 50-60\%), l-limonene, carvacrol, trans-carveol, $d$ dihydrocarveol, l-dihydrocarveol, etc.) have been identified as the constituents. It was reported that monoterpeneoids have also been identified in the water soluble extracts of caraway. Commercial caraway was extracted with $70 \%$ methanol at room temperature. After evaporation of the solvent, the residue was partitioned into ether-water, EtOAcwater. Removal of the solvent from each phase gave the ether, EtOAc and aqueous extracts, The aqueous extract was chromatographed over Amberlite XAD-II $\left(\mathrm{H}_{2} \mathrm{O}-\mathrm{MeOH}\right)$. The methanol eluate was subjected to Sephadex LH-20 (MeOH) to give eight fractions $(\mathrm{A}-\mathrm{H})$. Fraction B was chromatographed over silica gel $\left(\mathrm{CHCl}_{3}-\mathrm{MeOH}-\mathrm{H}_{2} \mathrm{O}\right.$ (17:3:0.2-4:1:0.17:3:0.5)-MeOH) to give 14 fractions $\left(\mathrm{B}_{1}-\mathrm{B}_{14}\right)$. Fraction $\mathrm{B}_{3}$ was passed through a Lobar RP-8 column (MeCN- $\mathrm{H}_{2} \mathrm{O}(3: 17)$ ) to give nine fractions $\left(\mathrm{B}_{3-1}-\mathrm{B}_{3-9}\right)$, and fraction $\mathrm{B}_{3-5}$ was subjected to HPLC (ODS, $\mathrm{MeCN}-\mathrm{H}_{2} \mathrm{O}$ (3:37)). The main fraction was acetylated with $\mathrm{Ac}_{2} \mathrm{O}$ and pyridine, and the acetylated fraction was subjected to HPLC (ODS, $\mathrm{MeCN}-\mathrm{H}_{2} \mathrm{O}(2: 3)$ ) to give two fractions. These two fractions were deacetylated by heating in a water bath with $5 \% \mathrm{NH}_{4} \mathrm{OH}-\mathrm{MeOH}$ for $2 \mathrm{~h}$, and passed through Sephadex $\mathrm{LH}-20(\mathrm{MeOH})$ to give (1R, $2 \mathrm{R}$, $4 S)$ - $p$-menthane-1,2,8-triol and Rel-(1S, 2S, 4R, 8R)-p-menthane-1,2,8-triol. Fraction $\mathrm{B}_{3-7}$ was subjected to HPLC (ODS, MeCN-H $\left.{ }_{2} \mathrm{O}(1: 9)\right)$ to give (1S, 2S, 4S, 8R)-p-menthane-2,8,9-triol; (1S, 2S, 4S, 8S)-p-menthane-2,8,9-triol; (1S, 2R, 4R, 8R)-p-menthane-2,8,9-triol and (1S, 2R, 4R, $8 \mathrm{R}$ )- $p$-menthane-2,8,9-triol. Fraction $\mathrm{B}_{3-7}$ was subjected to HPLC (ODS, MeCN- $\mathrm{H}_{2} \mathrm{O}$ (1:9) to give Rel-(1R, 2S, 4R, 8S)-p-menthane-2,8,9-triol; Rel-(1R, 2S, 4R, 8R)-p-menthane-2,8,9-triol; Rel-(1S, 2S, 4R, 8S)-p-menthane-2,8,9-triol and Rel-(1R, 2S, 4R, 8R)-p-menthane-2,8,9-triol. From this mixture, Rel-(1R, 2S, 4R, 8R)-p-menthane-2,8,9-triol was isolated by silica gel column chromatography $\left(\mathrm{CHCl}_{3}-\mathrm{MeOH}-\mathrm{H}_{2} \mathrm{O}(9: 1: 0.1)\right)$. Fraction $\mathrm{B}_{9}$ was subjected to a Lobar RP-8 column (MeCN-H $\left.\mathrm{H}_{2} \mathrm{O}(3: 17)\right)$ and HPLC (CHA, MeCN-H $\left.{ }_{2} \mathrm{O}(9: 1)\right)$ to give (1S, 2R, 4R, $8 \mathrm{~S})$ - $p$-menthane-2,8,9-triol-9-O- $\beta$-D-glucopyranoside respectively. Fraction $\mathrm{B}_{11}$ was also

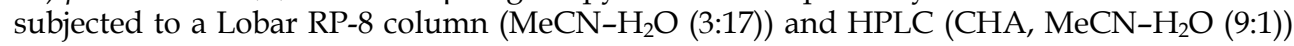
to give (1S, 2R, $4 S$ )- $p$-menthane-1,2,8-triol-8-O- $\beta$-D-glucopyranoside respectively. Fraction $\mathrm{B}_{10}$ was passed through a Lobar RP-8 column $\left(\mathrm{MeCN}_{-} \mathrm{H}_{2} \mathrm{O}(3: 17)\right)$ to give eight fractions $\left(\mathrm{B}_{10}\right.$ $\left.{ }_{1}-\mathrm{B}_{10-8}\right)$. Fraction $\mathrm{B}_{10-4}$, fraction $\mathrm{B}_{10-5}$ and $\mathrm{B}_{10-7}$ were subjected to HPLC (CHA, $\mathrm{MeCN}-\mathrm{H}_{2} \mathrm{O}$ $(9: 1))$ to give (1S, 2S, 4R)- $p$-menthane-1,2,10-triol-2-O- $\beta$-D-glucopyranoside, $(1 \mathrm{~S}, 2 \mathrm{~S}, 4 \mathrm{R}, 8 \mathrm{R})$ $p$-menthane-1,2,9-triol-2-O- $\beta$-D-glucopyranoside, and (1S, 2R, 4R, 8S)-p-menthane-2,8,9-triol4-O- $\beta$-D-glucopyranoside respectively (Matsumura et al., 2001).

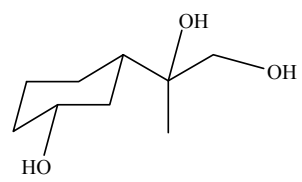

(1S, 2S, 4S, 8R)-p-menthane 2,8,9-triol

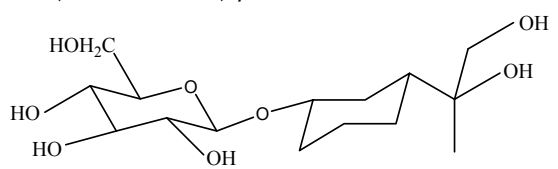

(1S, 2R, 4R, 8S)-p-menthane-2,8,9-triol-4-O- $\beta$-Dglucopyranoside

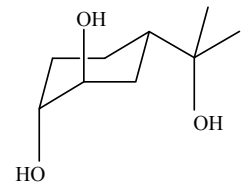

(1R, 2R, 4S)-p-menthane-1,2,8-triol

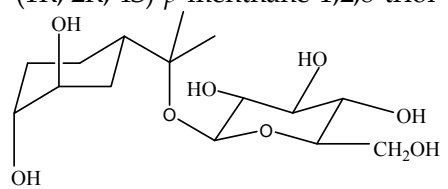

(1S, 2R, 4S)-p-menthane-1,2,8-triol-8-O- $\beta$-Dglucopyranoside 
Carvacrol, one of the essential oil components of Monarda punctata was obtained as a lipase inhibitor. Lipase is an enzyme that hydrolyzes triacylglycerols (TGs). The digestion and absorption of natural lipids begins with hydrolysis by pancreatic lipase. The activity of this enzyme greatly affects the metabolism of fat and the concentration of TG in blood. Recently, inhibitors of lipase and lipid absorption have been isolated from natural sources with the aim of preventing and treating metabolic syndrome. Monarda punctata L. (Lamiaceae) is a traditional herbal medicine of North American Indians used as a remedy for colds and a treatment for nausea, vomiting, and rheumatic pains. Carvacrol was obtained from $M$. punctata essential oil. Powdered whole plants of $M$. punctata were extracted with acetone$\mathrm{H}_{2} \mathrm{O}$ (80:20). The extract was suspended in $\mathrm{H}_{2} \mathrm{O}$, and extracted with $\mathrm{Et}_{2} \mathrm{O}$. The ether extract was suspended in $\mathrm{EtOH}-\mathrm{H}_{2} \mathrm{O}(8: 2)$, and extracted with hexane. The hexane soluble extract was passed through a silica gel column yielding 14 fractions, one of which, eluted with $\mathrm{CHCl}_{3}-\mathrm{MeOH}$ (99:1) was an essential oil fraction whose major component was carvacrol. The $\mathrm{H}_{2} \mathrm{O}$ layer extract was a red-brown syrup. It was dissolved again in $\mathrm{H}_{2} \mathrm{O}$, and the aqueous solution was passed through a porous polymer gel column and eluted with $\mathrm{H}_{2} \mathrm{O}$, $\mathrm{MeOH}-\mathrm{H}_{2} \mathrm{O}(80: 20)$ and $\mathrm{MeOH}$. The $\mathrm{MeOH}-\mathrm{H}_{2} \mathrm{O}$ (80:20) eluate was subjected to on a reversed-phase column chromatography using ODS (Cosmosil $140 \mathrm{C}_{18}$-OPN) and eluted with $20 \%, 30 \%, 40 \%, 50 \%, 60 \%, 80 \% \mathrm{MeOH}$ in $\mathrm{H}_{2} \mathrm{O}$, and $\mathrm{MeOH}$ (fractions $1 \mathrm{~A}-1 \mathrm{G}$ ). Fraction $1 \mathrm{C}$ was subjected to YCCC and HPLC, yielding monoterpenoid glycosides monardins (A-F) together with flavonoids and some other phenolic compounds (Yamada et al., 2010).

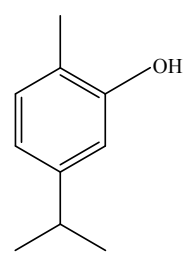

carvacrol

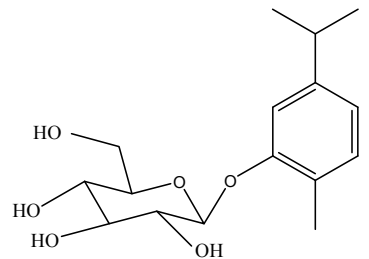

2-methyl-5-(1-methylethyl) phenyl $\beta$-D-glucopyranoside

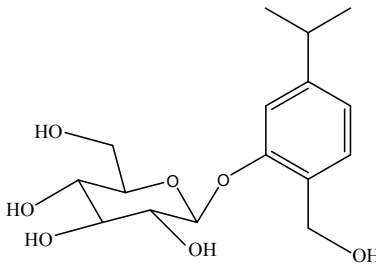

monardin C

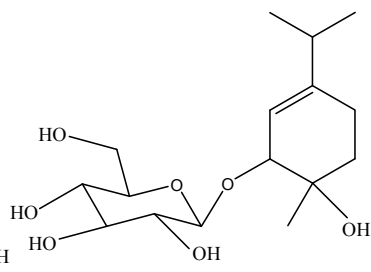

monardin E

\subsubsection{Sesquiterpenoids}

Sesquiterpenoids are generally synthesized by the mevalonate pathway and they are formed from three $C_{5}$ units (Dewick, 2009). The sesquiterpenoids which widely distributed in nature have similar properties to monoterpenoids and generally be less volatile than monoterpenoids (Robbers et al., 1996; Heinrich et al., 2004; Dewick, 2009). a-Bisabolol, a major component of matricaria (Matricaria chamomilla); $\gamma$-bisabolene which contributes to the aroma of ginger (Zingiber officinale); costunolide a bitter principle found in the roots of chicory (Cichorium intybus); parthenolide, an antimigraine agent in feverfew are some of the naturally occurring sesquiterpenoids (Dewick, 2009).

Artemisinin, antimalarial drug, is one of the most important sesquiterpene obtained from sweet wormwood, Artemisia annua L. (Asteraceae). This plant is known as Qinghao and has been used for the treatment of fevers and malaria in China for many centuries. The methyl ether of dihydroartemisinin that was developed for enhancing the solubility of the compound whilst retaining the biological activity is used clinically (Heinrich et al., 2004; Klayman et al., 1984). Artemisinin isolated from the leaves of A. annua. Petroleum ether extract of the plant was chromatographed on silica gel (70-230 mesh) using 7.5\% EtOAc in 
$\mathrm{CHCl}_{3}$ solvent system. Artemisinin was isolated as fine white crystals in second fraction (Klayman et al., 1984).

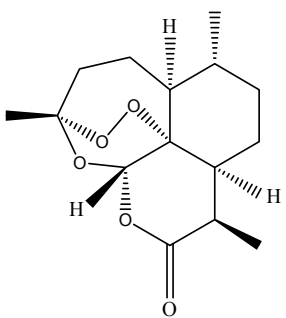

artemisinin

Curcuma zedoaria Roscoe (Zingiberaceae), also known as white turmeric, zedoaria or gajutsu, has been used for menstrual disorders, dyspepsia, vomiting and for cancer traditionally. This plant has also been used for the treatment of cervical cancer in Chinese traditional medicine. C. zedoaria rich source of essential oils and many sesquiterpenoids as well as curcuminoids have been isolated (Syu et al., 1998; Lobo et al., 2009). Zedoarol, germacrone, curdione, $\beta$-elemene and curzeone are sesquiterpenoids which were isolated from $C$. zedoaria Shiobara et al (1986). $\mathrm{CH}_{2} \mathrm{Cl}_{2}$ extracts of the plant was chromatographed on silica gel using hexane-EtOAc gradient. Fraction 11 was rechromatographed after evaporation on Sephadex $\mathrm{LH}-20$ using $\mathrm{CHCl}_{3}-\mathrm{MeOH}$ (1:1) to afford curzeone. Zedoarol obtained from separation of fraction 21 on silica gel using hexane-EtOAc (97:3) and sephadex $\mathrm{LH}-20\left(\mathrm{CHCl}_{3}-\mathrm{MeOH}, 1: 1\right)$ respectively. Further separation of fraction 63 on silica gel $\left(\mathrm{CH}_{2} \mathrm{Cl}_{2}\right)$ followed by on Sephadex $\mathrm{LH}-20\left(\mathrm{CHCl}_{3}-\mathrm{MeOH}, 1: 1\right)$ led to the isolation of germacrone (Shiobara et al., 1986). Ar-Turmerone and $\beta$-turmerone were obtained also from C. zedoaria rhizomes. Methanolic extract of the rhizomes were prepared and then was suspended in distilled water and partitioned with $\mathrm{CHCl}_{3}$. After evaporation $\mathrm{CHCl}_{3}$ extract was subjected to column chromatography on silica gel and eluted with gradient mixtures of $\mathrm{CHCl}_{3}$ and $\mathrm{MeOH}$ (20:1 to 1:1) to afford eight fractions. Further separation was performed on fraction 2 on silica gel by column chromatography eluting with $\mathrm{CHCl}_{3}$ and $\mathrm{MeOH}$ in increasing polarity (100:1 to 1:1) to obtain five subfractions. Subfraction 2 led to the isolation of arturmerone and $\beta$-turmerone after preparative TLC (hexane-EtOAc, 97:3) (Hong et al., 2001).<smiles>C=C1Cc2occ(Cl)c2C(=O)C2(C)C(C)CC[C@]12C</smiles><smiles>CC1=C2CC(=O)C(=C(C)CO)CC(=C(C)C2)CC1</smiles>

germacrone<smiles>C=CC1(C)CCC(C(=C)C)CC1C(=C)C</smiles>

$\beta$-elemene<smiles>CC(C)=CC(=O)C[C@@H](C)c1ccc(C)cc1</smiles>

ar-turmerone<smiles>Cc1cc2occ(C)c2c2c1CC[C@H](C)C2=O</smiles>

curzeone<smiles>C=C1C=CC([C@@H](C)CC(=O)C=C(C)C)CC1</smiles>

$\beta$ - turmerone 
Daucus carota L. (Umbelliferae) is widely distributed in the world. Fruits of the plant have been used commonly as a medicine for the treatment of ancylostomiasis, dropsy, chronic kidney diseases and bladder afflictions in Chinese medicine. Flavonoids, anthocyanins, chromones, coumarins as well as sesqiterpenoids have been isolated from the D. carota. Sesquiterpenoids were isolated from the fruits of the plant. Fruits of the plant were extracted with $95 \%$ aqueous $\mathrm{EtOH}$. Partition of the $\mathrm{EtOH}$ extract was performed with petroleum ether, $\mathrm{CHCl}_{3}$, EtOAc and $\mathrm{BuOH}$ respectively, after suspended in $\mathrm{H}_{2} \mathrm{O}$. The $\mathrm{CHCl}_{3}$ layer was fractionated on silica gel by column chromatography with gradient elution of petroleum ether-EtOAc (7:1-1:7) to yield 10 fractions. Fraction 6 was chromatographed on silica gel column chromatography petroleum ether-EtOAc (3:1-1:1) to give 5 subfractions. Subfraction 3 was separated by Sephadex $\mathrm{LH}-20$ with $\mathrm{MeOH}$ followed by silica gel $\mathrm{CHCl}_{3}-\mathrm{Et}_{2} \mathrm{O}$ (8:1) to obtain daucusol. Daucuside, a sesquiterpenoid glycoside was also isolated from the $\mathrm{BuOH}$ layer. Column chromatography on silica gel with eluting gradient of $\mathrm{CHCl}_{3}-\mathrm{Et}_{2} \mathrm{O}$ (15:1-8:1) allows obtaining eight fractions. Repeated column chromatography on silica gel with $\mathrm{CHCl}_{3}-\mathrm{MeOH}$ (9:1) provides five subfractions. Daucuside was obtained by purification of subfraction 2 using preparative HPLC (20\% aqueous MeOH) (Fu et al., 2010).

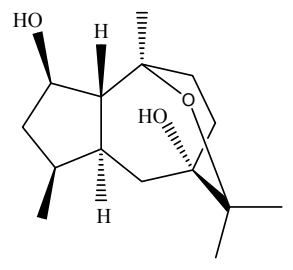

daucusol

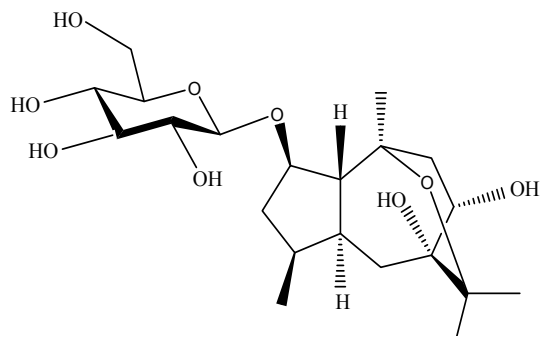

daucuside

Tanacetum parthenium (L.) Schultz. Bip. (Asteraceae) known as feverfew, leaves have been used as antipyretic or febrifuge. Recent studies have revealed that feverfew effective in migraine by substantially reducing the frequency and severity of the headache. Responsible compound appears to be parthenolide, a germacranolide type sesquiterpenoid lactone. Parthenolide was reported to act as serotonin antagonist resulting in an inhibition of the release of serotonin from blood platelets. Parthenolide was isolated from the leaves of $T$. parthenium. Extraction of the plant material was done after exhaustive maceration in ethanol-water (90:10) at room temperature in the dark. The extract was filtered, evaporated under vacuum, and lyophilized. Subsequently, the hydroalcoholic extract was chromatographed on a silica gel column with hexane, $\mathrm{CH}_{2} \mathrm{Cl}_{2}, \mathrm{EtOAc}, \mathrm{MeOH}$, and $\mathrm{MeOH}-$ $\mathrm{H}_{2} \mathrm{O}$ (90:10). Next, the $\mathrm{CH}_{2} \mathrm{Cl}_{2}$ fraction was chromatographed on a silica gel column with different mixtures of solvents. The hexane- $\mathrm{CH}_{2} \mathrm{Cl}_{2}$ fraction resulted in isolation of parthenolide (Robbers et al., 1998; Tiuman et al., 2005).

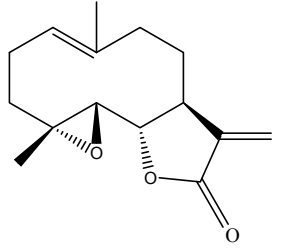

parthenolide 
Valeriana officinalis L. (Valerianaceae) known as valerian, is used in the treatment of conditions involving nervous excitability, such as hysterical states and hypochondriasis as well as insomnia. The main components of the valerian roots are the iridoids and volatile oil. Volatile oil contains numerous compounds including monoterpenoids, sesquiterpenoids (Heinrich et al., 2004). Valerenane sesquiterpeneoids were isolated from a $\mathrm{CH}_{2} \mathrm{Cl}_{2}$ extract of the Valeriana roots. Extract was concentrated and combined with $2 \% \mathrm{NaOH}$. Then aqueous layer were acidified and extracted with petroleum ether-Et $\mathrm{t}_{2} \mathrm{O}(2: 1)$ to obtain extract $\mathrm{A}$. The remaining $\mathrm{CH}_{2} \mathrm{Cl}_{2}$ extract was washed with $\mathrm{H}_{2} \mathrm{O}$ and concentrated under vacuum. The residue was dissolved in petroleum ether and concentrated after filtration to yield extract $\mathrm{B}$. Isolation procedure of extract $\mathrm{B}$ was performed on silica gel column using petroleum ether$\mathrm{Et}_{2} \mathrm{O}$ mixture in increasing polarity. Fractions 26-34 contains Z-valerenyl acetate and E-/Zvalerenyl isovalerate which were isolated by means of preparative TLC (hexane- $\mathrm{Et}_{2} \mathrm{O}, 4: 1$ ) followed by preparative GC. Extract A was dissolved in pentane and stored at $-20{ }^{\circ} \mathrm{C}$ after evaporation. Separation of the extract A was done using column chromatography on silica gel and eluted with petroleum ether- $\mathrm{Et}_{2} \mathrm{O}$ mixture from 10 upto $100 \%$. Valerenic acid and hydroxyvalerenic acid were obtained from the $20 \% \mathrm{Et}_{2} \mathrm{O}$ and $100 \% \mathrm{Et}_{2} \mathrm{O}$ fractions respectively by preparative TLC (hexane- $\left.\mathrm{Et}_{2} \mathrm{O}, 1: 4\right)$. Acetoxy valerenic acid was also obtained from remaining pentane extracts by preparative TLC using hexane- $\mathrm{Et}_{2} \mathrm{O}$ (3:2) (Bos et al., 1986).

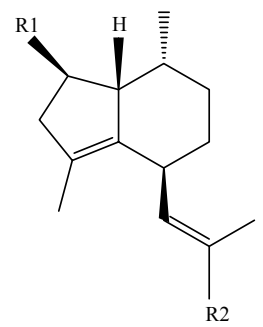

R1

R2

$\mathrm{CHO} \mathrm{H}$ valerenal

$\mathrm{COOH} \mathrm{H}$ valerenic acid

$\mathrm{COOH} \mathrm{OH}$ hydroxyvalerenic acid

$\mathrm{COOH} \mathrm{OAc}$ acetoxyvalerenic acid

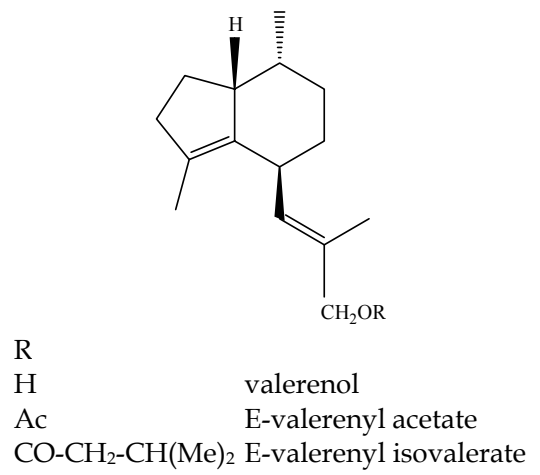




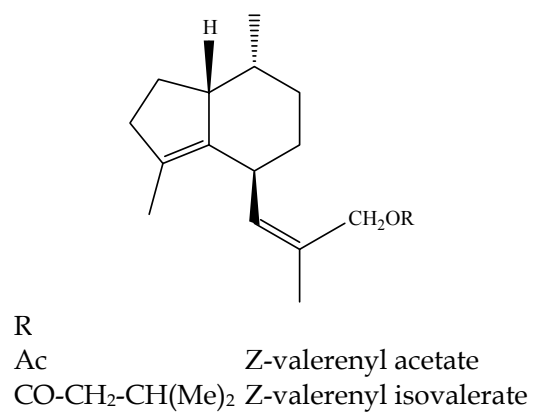

\subsubsection{Diterpenoids}

The diterpenoids are a large group of non-volatile terpenoids based on four isoprene units (Robbers et al., 1996).

Many of the diterpenoids are wood resin products. Abietic acid is the major component of colophony. Gibberellins are the best known plant hormones, taxol is used in the treatment of breast and ovarian cancer obtained from Pacific yew (Taxus bravifolia), are the known diterpenoids from nature (Hanson, 2003).

Taxol (Paclitaxel), a diterpenoid isolated from Taxus brevifolia Nutt. (Taxaceae), also known as the Pacific yew, used clinically in ovarian, breast, lung and prostate cancer effectively (Robbers et al., 1996; Wall \& Wani, 1996; Heinrich et al., 2004). Taxol has been isolated from T. brevifolia using many different chromatographic techniquies and one of the way was described by Senihl et al. (1984) which employs normal phase chromatography columns for the separation procedures and includes multiple (seven) steps respectively as follows; 1. Extraction with alcohol and concentration, 2. Partition between water and dichloromethane, 3. Filtration chromatography, 4. Silica column chromatography, 5. Alumina chromatography. 6. Medium pressure silica column chromatography, 7. Preparative HPLC. For the other analogues, two or three other chromatographic columns, followed by preperative HPLC, were used.

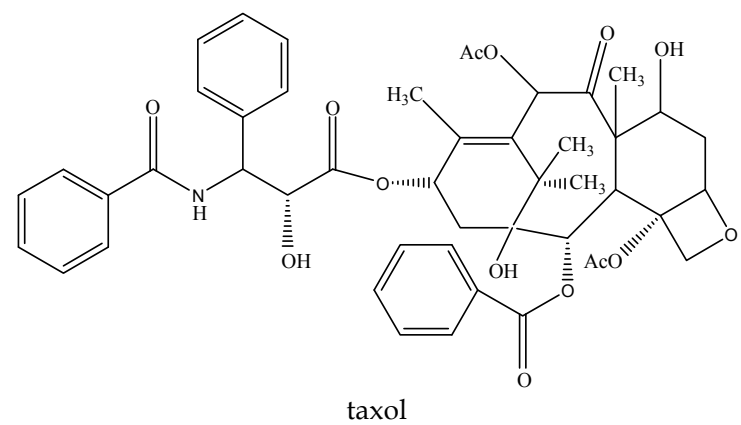

Ginkgo biloba, (Ginkgoaceae) one of the oldest living plant species dating back more than 200 million years, is often reffered to as "living fossil". Medicinal uses of G. biloba was described 
in the Chinese Materia Medica more than 2.000 years ago and is used to treat memory and cognitive impairment, for which it has moderate efficacy with minimal side effects. The ginkgo leaves contain many active ingredients, including flavonoids, terpene trilactones (Jacobs \& Browner, 2000). Triterpene lactones namely ginkgolides and flavonoids are believed to be associated with pharmacological activities of G. biloba extracts. While flavonoids can be obtained from many other plants, ginkgolides are unique compounents of the G. biloba extracts (Jaracz et al., 2004). It has been reported that flavone glycosides of the rutin type probably reduced the capillar fragility and reduce blood vessel which may prevent ischemic brain damage. Ginkgolides have been shown to inhibit platelet activating factor (PAF) as well as increasing blood fluidity and ciculation. In Europe ginkgo extract is sold as an approved drug (Robbers et al., 1996). It has been reported that many extraction methods have been developed for the extraction triterpene lactones efficiently such as using organic solvents, water, pressurized water or supercritical fluids. From these enriched extracts terpenic compounds can be separated by fractional recrystalization, repeated column chromatography, reversed phase HPLC, chromatography with Sephadex LH-20 or more efficiently by chromatography on NaOAc impregnated silica gel. In the following method was described by Jaracz et al. (2004) for the isolation of bilobalide and ginkgolides using column chromatography. The enriched triterpene trilactone extract was chromatographed on silica gel column. The column eluted with EtOAc-hexane solvent mixtures. The initial solvent system was EtOAc-hexane (3.5:6.5). Content of EtOAc in eluent was increased gradually in six steps to EtOAc-hexane (6.5:3.5). The fractions collected at EtOAc-hexane (4.5:5.5) contained bilobalide. Pure bilobalide was obtained as white powder after washing with $\mathrm{Et}_{2} \mathrm{O}$. The fractions collected at EtOAc/hexane (5:5) and (5.5:4.5) contained mixture of ginkgolide A/B and ginkgolide C/J, respectively. Ginkgolide mixtures were separated using further chromatographic methods to yield pure compounds (Jaracz et al., 2004). A simple preparative method for the isolation and purification of ginkgolides and bilobalide (ginkgo terpene trilactones) was also developed by Beek \& Lelyveld (1997). Ginkgo biloba leaf extracts were used for extraction. After a partition step with EtOAc, the enriched intermediate extract was separated into the individual terpenes by mediumpressure liquid chromatography on silica impregnated with $6.5 \% \mathrm{NaOAc}$ with a gradient from petroleum ether-EtOAc to EtOAc-MeOH. After recrystallization from $\mathrm{H}_{2} \mathrm{O}-\mathrm{MeOH}$, all ginkgolides could be isolated in high purity. After a selective extraction with $\mathrm{H}_{2} \mathrm{O}$, leaves could also be used as a starting material (Beek \& Lelyveld, 1997).

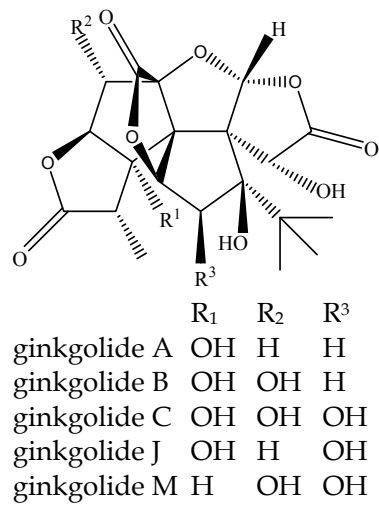




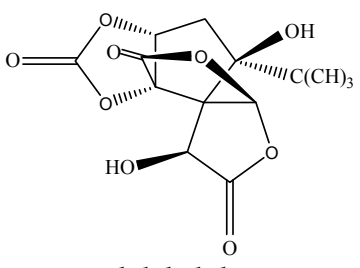

bilobalide

Salvia divinorum Epling \& Jativa is known as hallucinogenic mint and traditionally used by Mazatec Indians of Oaxaca, Mexico in traditional medicine primarily for its psychoactive effects (Giroud et al., 2000; D.Y.W.Lee et al., 2005). Salvinorin A, a neoclerodane diterpenoid has been isolated and identified as the responsible compound for psychoactive effects. Additionally, salvinorin A have found to have high affinity and selectivity for the kappa opioid receptor is one of the three main types of opioid receptors (D.Y.W.Lee et al., 2005). The discovery of kappa opioid receptor as the molecular target of salvinorin A has opened up many opportunities for drug discovery and drug development for a number of psychiatric and non-psychiatric disorders (Vortherms \& Roth, 2006; Li et al 2007). Salvinorin A isolated from the leaves of the $S$. divinorum. Dried leaves of the plant were sequentially extracted with hexane, acetone and $\mathrm{MeOH}$. The acetone extract was fractioned by flash column chromatography with an equal mixture of activated carbon Celite 545. The column was eluted with acetone and hexane. The supernatant of the acetone extract was chromatographed on a silica gel column and eluted with $\mathrm{CHCl}_{3}$-acetone to give five fractions. The fraction eluted with $\mathrm{CHCl}_{3}$-acetone (20:1) was subjected to repeated silica gel column chromatography with a gradient of hexane and EtOAc (15:1-1:1) to afford subfractions. Combined subfractions were purified on silica gel column by $\mathrm{CHCl}_{3}-\mathrm{EtOAc}$ (20:1-10:1) or hexane-EtOAc (5:1-2:1) solvent systems to yield salvinorin A together with other diterpenoids such as salvinorin $B,-C,-D,-E,-F,-G$, divinatorin $C,-D,-E$, hardwickiic acid (D.Y.W.Lee et al., 2005).

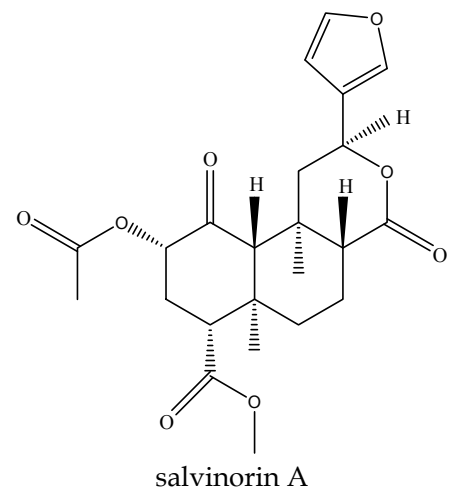

\subsubsection{Triterpenoids}

The triterpenoids are formed from six isoprene units biosynthetically and widely distributed in nature including plants, microorganisms, animals and humans. Typical examples of the triterpenoids are steroids which have many important functions in mammals such as sex hormones (Robbers et al., 1996; Heinrich et al., 2004). 
Oleanolic acid and its isomer ursolic acid are triterpenoids that exist widely in plants as well as in foods as their free forms or as their glycosides. Oleanolic acid and ursolic acid are well known for their hepatoprotective effects. They are used alone or in combination with other hepatoprotective ingredients as oral medications (Liu, 1995; 2005). It has also been reported that oleanolic acid and ursolic acid act at various stages of tumor development to inhibit tumor initiation and promotion, as well as to induce tumor cell differentiation and apoptosis (Liu, 2005). Oleanolic acid and ursolic acid have been isolated many natural sources. Oleanolic acid was obtained from grape as antimicrobial compound. Raisins were extracted with $\mathrm{MeOH}$ by maceration. The extract was concentrated and suspended in $\% 90 \mathrm{MeOH}$ and then partitioned with hexane, $\mathrm{CHCl}_{3}$ and EtOAc respectively. The hexane soluble extract was subjected to silica gel column chromatography and eluted with mixture of $\mathrm{CHCl}_{3}-\mathrm{MeOH}$ (1:0-0:1) to give nine fractions. Fraction 3 was separated on silica gel VLC column and eluted with hexane:isopropyl alcohol gradient mixtures (98:2 - 50:50) to yield oleanolic acid (Rivero-Cruz et al., 2008). Another example can be given for oleanolic acid isolation from Salvia officinalis. Leaves of the Salvia officinalis were extracted with $\mathrm{MeOH}$ and then extract was partitioned with EtOAc and $\mathrm{n}-\mathrm{BuOH}$ respectively. EtOAc fraction was chromatographed on silica gel column chromatography using following solvent systems hexane-EtOAc (10:1-3:1-1:1)- $\mathrm{CHCl}_{3}-\mathrm{MeOH}$ (10:1)-MeOH to give 4 fractions. Fractions 2 and 3 give diterpenes as well as oleanolic acid after column chromatography on ODS (MeOH$\mathrm{H}_{2} \mathrm{O}$ 60:40-90:10) followed by preparative HPLC ( $\left.\mathrm{MeOH}-\mathrm{H}_{2} \mathrm{O}, 85: 15\right)$ (Ninomiya et al., 2004).

Ursolic acid was isolated from Sambucus ebulus L. (Elder) as anti-inflammatory agent. Isolation was carried out from ethanolic extract of the dwarf elder. Initial seperation was performed by means of liquid-liquid extraction of the crude extract with petroleum ether, diethyl ether, EtOAc and $\mathrm{BuOH}$ respectively. Diethyl ether fraction was subjected to silica gel column chromatography and petroleum ether and increasing amounts of ethyl acetate was used as mobile phase to afford eight fractions. Fraction 4 was divided in $\mathrm{CH}_{2} \mathrm{Cl}_{2}$ as soluble and insoluble part. $\mathrm{CH}_{2} \mathrm{Cl}_{2}$ insoluble part was subjected to liquid-liquid using petroleum ether, EtOAc, ACN and butyl-methyl ether (10:1:5:2). The lower layer was separated by high-speed counter current chromatography (HSCCC) using petroleum ether, EtOAc, ACN and butylmethyl ether (10:1:5:2) to obtain three fractions and remained insoluble part. Insoluble part subjected to crystallization with mixture of ACN and tetrahydrofuran to afford ursolic acid as white platelets (Schwaiger et al., 2011). Ursolic acid was also obtained from many of the plants. One of them is Orthosiphon stamineus Benth., (Lamiaceae), a native plant to tropical Eastern Asia. Dried leaves of the plant were extracted with $\mathrm{MeOH}$. After filtration and concentration, the crude extract was suspended in $\mathrm{H}_{2} \mathrm{O}$ and partitioned with hexane, $\mathrm{CHCl}_{3}, \mathrm{EtOAc}$ and $\mathrm{BuOH}$. The $\mathrm{CHCl}_{3}$ soluble fraction was applied to silica gel column chromatography and eluted with EtOAc-hexane (7:3) to yield 5 fraction. Further purification by preparative TLC using EtOAc-hexane (3:2) led to the isolation of ursolic acid (Hossain \& Ismail, 2010).

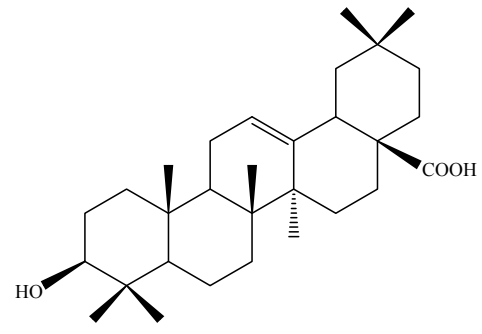

oleanolic acid

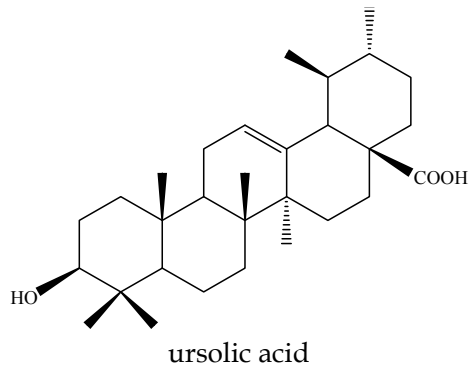

ursolic acid 
Curcurbita pepo (pumpkin) belongs to Cucurbitaceae family is used as a vegetable for human consumption and also use in traditional medicine. Cucurbita pepo is used in the therapy of minor disorders of the prostate gland and the urinary bladder. Cucurbita pepo has received considerable attention in recent years because of the nutritional and health values of the seeds. The seeds are excellent source of protein and also pharmacological activity such as antidiabetic, anti fungal and antioxidant. Diets riched in pumpkin seeds have also been associated with lower levels of gastric, breast, lung and colorectal cancer. Seeds and fruit parts of cucurbits are reported to possess purgative, emetic and antihelmintic properties due to the secondary metabolite cucurbitacin content. Cucurbitacins are important functional component found in Cucurbitaceae and constitute a group of diverse triterpenoid substances which are well known for their bitterness and toxicity. They are highly oxygenated, tetracyclic triterpenes containing a cucurbitane skeleton and they are divided into twelve categories which range from cucurbitacins A to T. Specific forms of cucurbitacins are known to have varying potencies with regard to particular activities and effects. It is known that, for example, cucurbitacins B and D are the most potent feeding stimulants for diabroticite beetles, while cucurbitacin $\mathrm{D}$ exhibits anti-ovulatory activity in mice, and cucurbitacin B, D, and E all exhibit cytotoxic and anti-tumor effects. Several cucurbitane and hexanorcucurbitane glycosides and other types of triterpenoids have been isolated from the fruits of Cucurbita pepo (Gill \& Bali, 2011). To obtain cucurbitacins, a liquid is obtained from cucurbitacin-containing plant material by compressing is extracted with a non-polar solvent to remove waxes, pigments, fatty acids, lipids and terpenes from the cucurbitacin-containing solution. For isolation and separation of cucurbitacins, retaining aqueous cucurbitacins-containing liquid is applied to a silica gel column chromatography, preferably the flash column chromatography. Elution is performed with a moderately polar solvent (e.g., $\mathrm{CH}_{3} \mathrm{Cl}$ ) firstly and then the column is eluted with a suitable mixture of solvents (e.g., $\mathrm{CH}_{3} \mathrm{Cl}$ and acetone, toluene and acetone, EtOAc and acetone, or $\mathrm{CH}_{3} \mathrm{Cl}$ and acetone), preferably in a ratio of about $95: 5$ by volume. This elution is collected essentially consists of the cucurbitacin $B$, which may then be additionally purified and dried. Then column is eluted with a second suitable mixture of solvents (e.g., $\mathrm{CH}_{3} \mathrm{Cl}$, acetone and $\mathrm{MeOH}$; EtOAc, acetone and $\mathrm{MeOH}$; or $\mathrm{CH}_{3} \mathrm{Cl}$, acetone and $\mathrm{MeOH}$ ), preferably in a ratio of about 90:5:5 by volume. This elution is collected essentially contains cucurbitacin D. Finally, the silica gel column is eluted with a third suitable solvent mixture (e.g., $\mathrm{CH}_{3} \mathrm{Cl}$, acetone and $\mathrm{MeOH}$; EtOAc, acetone and $\mathrm{MeOH}$; or $\mathrm{CH}_{3} \mathrm{Cl}$, acetone and $\mathrm{MeOH}$ ), preferably in a ratio of 80:5:15 by volume. This elution is collected mainly consists of the cucurbitacin E (Subbiah, 1999).

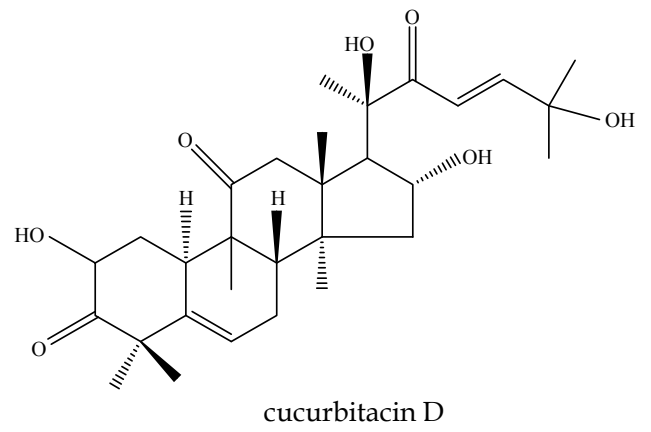


Centella asiatica (L.) Urban (Umbelliferae) (Gotu kola), is widely cultivated as a spice or vegetable and is used in treatment of skin diseases, rheumatism, inflammation mental illness, epilepsy, diarrhea and wounds. Polyacetylenes, flavonoids and triterpenoids have been isolated from this plant and among them triterpenoids are major and the most important components of $C$. asiatica, regarded as a marker constituent in terms of quality control. The triterpenes obtained from $C$. asiatica are mainly pentacyclic triterpenic acids and their respective glycosides, belonging to ursane- or oleanane-type, including asiatic acid, asiaticoside, madecassic acid, madecassoside, brahmoside, brahmic acid, brahminoside, thankuniside, isothankuniside, centelloside, madasiatic acid, centic acid, cenellic acid, betulinic acid, indocentic acid, etc (Zeng \& Qin, 2007; Nhiem et al., 2011). Chromatographic separation of the triterpenoids and their glycosides were performed from methanolic extract of the plant leaves. $\mathrm{MeOH}$ extract was suspended in $\mathrm{H}_{2} \mathrm{O}$ and partitioned with EtOAc. EtOAc soluble fraction was then subjected to column chromatography on silica gel and eluted with gradient of $\mathrm{CHCl}_{3}-\mathrm{MeOH}$ (50:1-1:50) to yield five fraction. Fraction 1 was rechromatographed on silica gel using $\mathrm{CHCl}_{3}-\mathrm{MeOH}(10: 1)$ as an eluent to give four subfractions. Subfraction 3-4 give asiatic acid and quadranoside IV after purification on RP-18 column with $\mathrm{MeOH}-\mathrm{H}_{2} \mathrm{O}$ (5:1) and $\mathrm{MeOH}-\mathrm{H}_{2} \mathrm{O}$ (4:1) respectively. The $\mathrm{H}_{2} \mathrm{O}$ soluble fraction was chromatographed on Diaion $\mathrm{HP}-20 \mathrm{P}$ column eluted with step gradient of $\mathrm{MeOH}$ in $\mathrm{H}_{2} \mathrm{O}$ yielding the five fractions. Fraction 2 was rechromatographed on RP-18 column and eluted with acetone $/ \mathrm{H}_{2} \mathrm{O}(2: 1)$ to yield four subfractions. Subfraction 1 was separated on a silica gel column using $\mathrm{CHCl}_{3} / \mathrm{MeOH} / \mathrm{H}_{2} \mathrm{O}$ (30:10:1) as solvent system to afford asiaticoside G. Asiaticoside and asiaticoside F were obtained from subfraction 2 by means of further purification on silica gel column using $\mathrm{CHCl}_{3}$ $\mathrm{MeOH}-\mathrm{H}_{2} \mathrm{O}$ (35:10:1) (Nhiem et al., 2011).

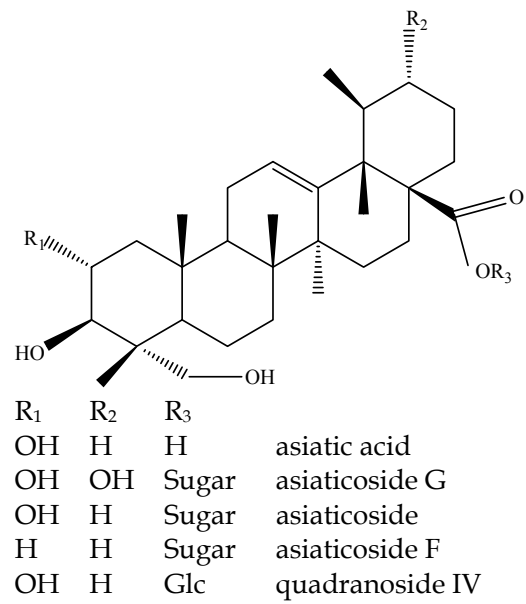

Calendula officinalis L., (Asteraceae), (Marigold) is popular medicinal herb and cosmetic in Europe and in America. This plant has been recorded various national pharmacopoeias as well as European Pharmacopoeia. Marigold has been used for wound healing and topical anti-inflammation. The anti-inflammatory properties of the plant flowers have been attributed to triterpenoids some of which are lauryl, myristoyl and palmitoyl esters of faradiol. Calendula flowers were extracted using supercritical fluid extraction method under 500 bar pressure, $50{ }^{\circ} \mathrm{C}$ and $35 \mathrm{~kg} \mathrm{~h}^{-1}$ carbon dioxide flow. Prepared extract was separated on 
silica gel column chromatography and eluted with petroleum ether- $\mathrm{CHCl}_{3}-\mathrm{MeOH}$ (50:49:1) to yield four fractions. Fraction 4, containing triterpenoid esters, was rechromatographed using low-pressure liquid chromatography on Lobar LiChroprep RP-18. Elution was carried out using $\mathrm{MeOH}$ to obtain nine subfractions. Fraction 3 gives faradiol-3-O-laurate. Faradiol3-O-myristate and faradiol-3-O-palmitate was obtained from fraction 4 and maniladiol-3-Omyristate as well as maniladiol-3-O-palmitate were purified from fraction 5 by further separations in HPLC (Hamburger et al., 2003).

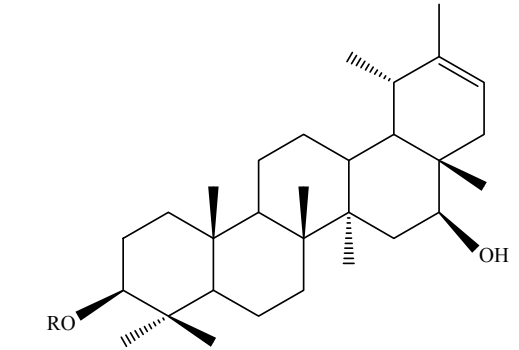

$\mathrm{R}=$ laurate

$\mathrm{R}=$ myristate

$\mathrm{R}=$ palmitate
faradiol-3-O-laurate faradiol-3-O-myristate faradiol-3-O-palmitate

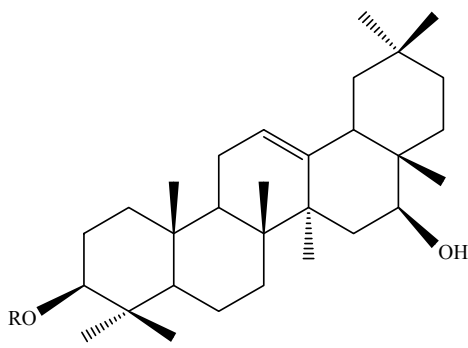

$\mathrm{R}=$ myristate $\mathrm{R}=$ palmitate
maniladiol-3-O-myristate maniladiol-3-O-palmitate

Panax ginseng C.A. Meyer has been used as a traditional medicine in China for thousand of years. Ginseng root is one of the most important oriental medicines and is used worldwide to combat stress and disturbances of the central nervous system, for hypothermia, for its antioxidant and organ-protective actions, and for radio-protection. The name "ginseng" often leads to some confusion due to its use for different plants with different phytochemical constituents. True ginsengs are plants in the genus Panax from which Asian ginseng (Panax ginseng) and American ginseng (Panax quinquefolium) have received the most interest for phytomedicinal use. However, Eleutherococcus senticosis, a completely different plant not even in the genus Panax, is sometimes referred to as Russian or Siberian "ginseng" (Briksin 2000; Fukuda et al., 2000; Park et al., 2002; Ruan et al., 2010). There are two types of preparations from ginseng: white ginseng prepared by drying after peelling off and red ginseng prepared by steaming and drying (Shibata, 2001). Ginseng root contains dammarane and oleanane type saponins as well as polyacetylene derivatives and polysaccharides. Triterpene saponins called as ginsenosides are the well known chemical constituents of ginseng. More than 30 ginsenosides have been identified in ginseng. Ginsenosides $R b_{1}, R b_{2}, R c, R d, R g_{1}, R_{2}$ and $R e$ are the major constituents of white and red ginsengs. However $\operatorname{Rg}_{3}, \mathrm{Rg}_{5}, \mathrm{Rg}_{6}, \mathrm{Rs}_{1}, \mathrm{Rs}_{2}$ and $\mathrm{Rs}_{3}$ are known to be only compounds that have been isolated from red ginseng (Park et al., 2002). Some partly deglycosylated saponins such as $R h_{1}, \mathrm{Rh}_{2}$ and $\mathrm{Rg}_{3}$ are obtained from red ginseng as artifacts produced during steaming (Shibata, 2001). Ginsenosides, Rb1, Rb2, Rc, Rd, Re, Rf, Rg1, and Rg2 are considered to be the most relevant for pharmacological activity (Briskin, 2000). Ruan et al. (2010) isolated a new ginsenosides from fresh roots of Panax ginseng together with known ginsenosides $\mathrm{Rb}_{1}, \mathrm{Rb}_{2}$, Rc and $\mathrm{Rd}$. Ginseng roots was extracted with $\mathrm{MeOH}-\mathrm{H}_{2} \mathrm{O}$ (4:1) five times and then extract was concentrated to dryness under reduced pressure at $40{ }^{\circ} \mathrm{C}$. The crude extract was suspended in $\mathrm{H}_{2} \mathrm{O}$ and subjected to D-101 resin column chromatography using $\mathrm{MeOH}-\mathrm{H}_{2} \mathrm{O}(0: 1,3: 2)$ as eluents to afford total ginsenosides. Total ginsenosides was applied to silica gel column and eluted with $\mathrm{CHCl}_{3}-\mathrm{MeOH}-\mathrm{H}_{2} \mathrm{O}$ (6:4:1) to 
yield three fractions. Fraction 1 was further chromatographed on preparative HPLC eluted with gradient $\mathrm{CH}_{3} \mathrm{CN}-\mathrm{H}_{2} \mathrm{O} 20 \%$ to $50 \%$ ) to give the ginsenoside $\mathrm{Rb}_{1}, \mathrm{Rb}_{2}$, $\mathrm{Rc}$ and $\mathrm{Rd}$ and $\mathrm{Ra} 3$ (Ruan et al. 2010). In another study ginsenosides were isolated from dried rootlet of ginseng which was steamed at 120 for 3 hours in an autoclave. Steamed ginseng was extracted with $\mathrm{MeOH}$ under reflux for $2 \mathrm{hr}$. The solvent was removed in vacuo to yield $\mathrm{MeOH}$ extract, which was suspended in water and extracted with $\mathrm{CH}_{2} \mathrm{CI}_{2}$. The remaining aqueous layer was extracted with water-saturated $\mathrm{n}-\mathrm{BuOH}$ The $\mathrm{n}-\mathrm{BuOH}$ fraction was concentrated in vacuo to yield $\mathrm{BuOH}$ fraction, which was subjected to silica gel column chromatography. Five fractions were obtained using stepwise gradient elution (EtOAc-MeOH- $\mathrm{H}_{2} 0$, 40:1: 1 - 10:1: 1). Fraction 3 was chromatographed over silica gel using EtOAc-MeOH- $\mathrm{H}_{2} \mathrm{O}=$ 25:1:1 solvent. Ginsenosides $\mathrm{Rs}_{4}$ and $\mathrm{Rs}_{5}$ were obtained from fraction 3, which were further purified on Ag-impregnated preparative TLC using EtOAc- $\mathrm{MeOH}-\mathrm{H}_{2}$ 0, 15:1:1 solvent. They were further purified over semi-preparative HPLC using a reverse-phase column (LiChrospher $100 \mathrm{RP}-18,250 \mathrm{~mm} \times 10$ mm i.d.) with $60 \% \mathrm{CH}_{3} \mathrm{CN}$ eluent to isolate ginsenoside $\mathrm{Rs}_{4}$ and $\mathrm{Rs}_{5}$. Fraction 2 was chromatographed over silica gel using hexane-isopropyl alcohol $=6: 1$ solvent to give $\mathrm{Rs}_{6}$ and Rs7 rich fractions. The fractions were further purified by semi-preparative HPLC using a reverse-phase column (LiChrospher $100 \mathrm{RP}-18,250 \mathrm{~mm}$ xl0 $\mathrm{mm}$ i.d.) with 50\% ACN eluent to yield ginsenosides $\mathrm{Rs}_{6}$ and $\mathrm{Rs}_{7}$ (Park et al., 2002).

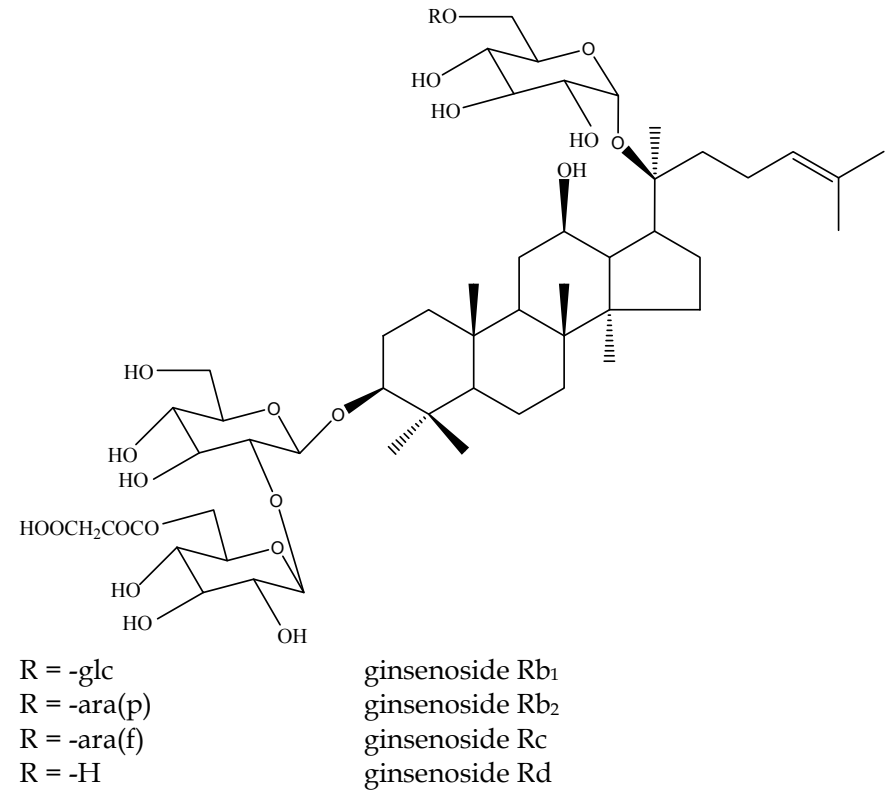

Ganoderma lucidum (Fr.) P. Karst. belongs to the family of Ganodermataceae (Basidiomyetes), has been used since ancient times. G. lucidum was believed to cure many kinds of diseases, and it was considered as an elixir that could revive the dead by the ancient people. $G$. lucidum possess important biological activities including anti-tumor, antimicrobial, antiviral (especially anti-HIV activities) and antiaging activities. It has been reported since the first triterpenoid ganoderic acid A was reported more than 150 compounds have been identified from Ganoderma spp. Triterpenoids are main components of this genus and have importance 
for their pharmacologic properties (Cheng et al., 2010). The air-dried and powdered fruit bodies of G. lucidum were extracted with $\mathrm{EtOH}-\mathrm{H}_{2} \mathrm{O}$. The crude extract was washed with petroleum ether to remove fatty acids, then extracted with $\mathrm{CH}_{2} \mathrm{Cl}_{2}$ to give the total triterpenoids fraction. An aliquot of the $\mathrm{CH}_{2} \mathrm{Cl}_{2}$ extract was applied to a silica gel column eluted successively with $\mathrm{CHCl}_{3}-\mathrm{MeOH}$ (200:1-1:1 gradient system) to obtain 5 fractions. Fraction 2 was subjected to a silica gel column eluted with petroleum ether-EtOAc (10:1-1:1 gradient system) to afford six fractions, F21-F26. F21 was subjected to Sephadex LH-20 column chromatography (petroleum ether- $\mathrm{CHCl}_{3}-\mathrm{MeOH}, 2: 1: 1$ ), then recrystallized to afford ganoderic acid DM. F22 was applied to a Sephadex LH-20 (petroleum ether- $\mathrm{CHCl}_{3}-$ $\mathrm{MeOH}, 2: 1: 1)$, and then further purified by semipreparative HPLC $\left(\mathrm{MeOH}-\mathrm{H}_{2} \mathrm{O}, 90: 10\right)$ to afford ganodermanondiol and ganoderic acid T-Q. F23 was recrystallized to obtain lucidadiol, F24 was extensively subjected to silica gel column chromatography (petroleum ether- $\left.\mathrm{CHCl}_{3}-\mathrm{Me}_{2} \mathrm{CO}, 8: 1: 1\right)$, Sephadex $\mathrm{LH}-20$, and then further purified by semipreparative HPLC to give ganoderol B, lucidumol A and 15a-hydroxy-3-oxo-5a-lanosta-7,9,24(E)-trien26-oic acid. F25 was purified by semipreparative HPLC $\left(\mathrm{MeOH}-\mathrm{H}_{2} \mathrm{O}, 70: 30\right.$, detection wavelength, $252 \mathrm{~nm}$ ) to give $3 \beta$-hydroxy-5a-lanosta-7,9,24(E)-triene-26-oic acid and 15a,26dihydroxy-5a-lanosta-7,9,24(E)-trien-3-one. F26 was applied to a succession silica gel column (400-600 mesh, $\mathrm{CHCl}_{3}-\mathrm{MeOH}, 100: 1-10: 1$ gradient system) and Sephadex LH-20 (PE$\left.\mathrm{CHCl}_{3}-\mathrm{MeOH}, 2: 1: 1\right)$ chromatography to afford 3 $\beta$-hydroxy-7-oxo-5a-lanosta-8,24(E)-dien26-oic acid, ganodermanontriol, $3 \beta, 7 \beta$-dihyroxy- $12 \beta$-acetoxy-11,15,23-trioxo-5a -lanosta-8en-26-oic acid methyl ester, ganoderiol $\mathrm{F}$ and lucideric acid $\mathrm{A}$. In the same manner, F3 was applied to a silica gel column (400-600 mesh) eluted with PE (60-90 C)- $\mathrm{Me}_{2} \mathrm{CO}$ (7:1-3:1) to afford 6 fractions, F31-F36. Each fraction was subjected to silica gel column chromatography and repeated semipreparative HPLC to afford ganoderic acid D, 11a-hydroxy-3,7-dioxo-5a lanosta-8,24(E)-dien-26-oic acid, 11 $\beta$-hydroxy-3,7-dioxo-5a -lanosta-8,24(E)-dien-26-oic acid, lucidone A, ganolucidic acid E, 4,4,14, a-trimethyl- 3,7-dioxo-5a -chol-8-en-24-oic acid, ganoderic acid $\mathrm{F}$ ganoderenic acid $\mathrm{D}$, ganoderic acid $\mathrm{E}$, ganoderic acid $\mathrm{J}$, ganoderenic acid $\mathrm{F}$. F4 was separated by repeated column chromatography $\left(\mathrm{CHCl}_{3}-\mathrm{MeOH}, 100: 1-5: 1\right.$ gradient system) and semipreparative HPLC $\left(\mathrm{MeOH}-\mathrm{H}_{2} \mathrm{O}, 40: 60\right.$, detection wavelength, $\left.252 \mathrm{~nm}\right)$ to afford ganoderic acid $\mathrm{B}$, ganoderic acid $\mathrm{A}, 7 \beta, 12 \beta$-dihydroxy-3,11,15,23-tetraoxo-5alanosta-8-en-26-oic acid, 12 $\beta$-hydroxy-3,7,11,15,23-pentaoxo-5a-lanosta-8-en-26-oic acid,

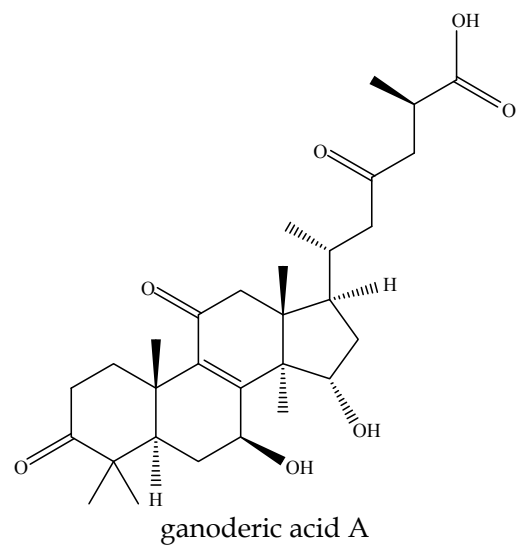


ganoderenic acid $B$, methyl ganoderate $H, 12 \beta$-acetoxy-7 $\beta$-hydroxy-3,11,15,23-tetraoxo-5a lanosta-8,20-dien-26-oic acid, methyl ganoderic acid $\mathrm{B}, 12 \beta$-acetoxy- $3 \beta, 7 \beta$-dihydroxy11,15,23-trioxo-5a-lanosta-8,20-dien-26-oic acid, ganolucidic acid A, methyl lucidenate $\mathrm{C}$, $12 \beta$-acetoxy-3,7,11,15,23-pentaoxo-5a -lanosta-8-en-26-oic acid ethyl ester, ganoderic acid $\mathrm{H}$ and ganoderic acid AM1. Whereas fraction F5 was separated by repeated column chromatography $\left(\mathrm{CHCl}_{3}-\mathrm{MeOH}, 100: 1-1: 1\right.$ gradient system) and semipreparative HPLC $\left(\mathrm{MeOH}-\mathrm{H}_{2} \mathrm{O}\right.$, 30:70, detection wavelength, $252 \mathrm{~nm}$ ) to give compounds $3 \beta, 7 \beta, 15 \mathrm{a}-$ trihydroxy-11,23-dioxo-5a-lanosta-8-en-26-oic acid, ganoderic acid $\mathrm{K}$, ganoderic acid G, ganoderenic acid A (Cheng et al., 2010).

Cimicifuga racemosa or Actaea racemosa L. (Black cohosh), Ranunculaceae, is known as wellknown herbal medicine with health benefits in treating painful menstrual periods and menopausal disorders. This plant is used primarily as a hormon-free phytomedicine in the treatment of climacteric symptoms related to menopause. It has been clarified that main components of the rhizoma are cycloartane type triterpenoids and their glycosides such as actein, 27-deoxyactein and several cimicifugosides as well as isoflavones, alkaloids and phenylpropanoids have been identified in Black cohosh (Chen et al., 2002; Watanabe et al., 2002; Heinrich et al., 2004; Z.Ali et al., 2007; Li et al., 2007; Borelli \& Ermst, 2008; Nian et al., 2011). Chen et al. (2002) isolated actein, 26-deoxyactein and 23-epi-26-deoxyactein from the rhizomes of $A$. racemosa. Rhizomes of the plant were extracted with $\mathrm{MeOH}$ and then concentrated under vacuum to yield a syrup residue. A sample of the residue was suspended in $\mathrm{H}_{2} \mathrm{O}-\mathrm{MeOH}$ (9:1) and fractionated by successive partitions with EtOAc and $\mathrm{BuOH}$ respectively. The EtOAc-soluble fraction was subjected to column chromatography on silica gel and eluted with $\mathrm{CHCl}_{3}, \mathrm{CHCl}_{3}-\mathrm{MeOH}(10,20,30,40,50,75 \%)$ and $\mathrm{MeOH}$ respectively to afford 8 fractions. Fraction 5 was subjected to a normal phase silica gel column chromatography by elution of petroleum ether-EtOAc mixture in increasing polarity to give 10 subfractions. 26-deoxyactein was obtained by direct crystallization from subfraction 5 . The main liquor was sequentially subjected to RP-18 chromatographic column separation eluted by $\mathrm{ACN}-\mathrm{H}_{2} \mathrm{O}$ followed by normal phase silica gel separation eluted by petroleum ether-EtOAc-MeOH (10:7:0.5) to obtain actein. Subfraction 3 was subjected to a RP-18 column separation eluted by $\mathrm{ACN}-\mathrm{H}_{2} \mathrm{O}$ and $\mathrm{MeOH}-\mathrm{H}_{2} \mathrm{O}$ followed by silica gel column separation eluted with petroleum ether-EtOAc-MeOH (10:5:0.5) to yield 23-epi-26deoxyactein (Chen et al., 2002). Another isolation procedure was described by Watanabe et al. (2002). Methanolic extract of the rhizomes of $C$. racemosa was concentrated under vacuum and the viscous concentrate was passed through a Diaion HP-20 column and eluted with $30 \% \mathrm{MeOH}, 50 \% \mathrm{MeOH}, \mathrm{MeOH}, \mathrm{EtOH}$ and EtOAc successively. Fractions eluted with 50\% $\mathrm{MeOH}$ were subjected to column chromatography on silica gel eluting with stepwise gradient mixtures of $\mathrm{CHCl}_{3}-\mathrm{MeOH}-\mathrm{H}_{2} \mathrm{O}$ (19:1:0, 9:1:0, 40:10:1, 20:10:1) and finally with $\mathrm{MeOH}$ to afford 7 fractions. Fraction 4 rechromatographed on silica gel column chromatography eluting with $\mathrm{CHCl}_{3}-\mathrm{MeOH}(30: 1,10: 1,5: 1)$ and ODS silica gel with $\mathrm{MeOH}-$ $\mathrm{H}_{2} \mathrm{O}(8: 5)$ to give 25-O-acetyl-12 $\beta$-hydroxycimigenol 3-O-a-L-arabinopyranoside. Fraction 5 gave $12 \beta$-hydroxycimigenol 3-O-a-L-arabinopyranoside after separation on ODS silica gel column chromatography eluted with $\mathrm{MeOH}-\mathrm{H}_{2} \mathrm{O}(8: 5)$. Fraction 7 was chromatographed on silica gel eluting with $\mathrm{CHCl}_{3}-\mathrm{MeOH}$ (9:1) and ODS silica gel with $\mathrm{MeOH}-\mathrm{H}_{2} \mathrm{O}$ (4:3) respectively to obtain $12 \beta, 21$-dihydroxycimigenol 3-O-a-L-arabinopyranoside. The $\mathrm{MeOH}$ eluate portion was separated on silica gel and eluted with $\mathrm{CHCl}_{3}-\mathrm{MeOH}(19: 1,9: 1,4: 1,2: 1)$ mixture and $\mathrm{MeOH}$ finally to yield four fractions. Fraction 2 was subjected to column 
chromatography on silica gel and eluted with $\mathrm{CHCl}_{3}-\mathrm{MeOH}$ to obtain two subfractions (2a$2 b)$. Subfraction 2a suspended in $\mathrm{MeOH}$ and after filtration rechromatographed on silica gel column chromatography eluting with $\mathrm{CHCl}_{3}-\mathrm{MeOH}(30: 1,19: 1)$ and ODS silica gel with ACN- $\mathrm{H}_{2} \mathrm{O}$ (1:1) and $\mathrm{MeOH}-\mathrm{H}_{2} \mathrm{O}$ (8:3) as well as on Sephadex LH-20 with $\mathrm{MeOH}$ respectively to obtain cimicigenol 3-O-a-L-arabinopyranoside, 25-O-methoxycimicigenol 3$\mathrm{O}$-a-L-arabinopyranoside, 23-O-acetylshengmanol 3-O-a-L-arabinopyranoside, 27deoxyactein and actein. The remain subfraction $2 b$ led to the isolation of cimiracemoside $F$, cimiracemoside G, cimiracemoside $H$ and 822R, 23R, 24R)-12 $\beta$-acetyloxy-16 $\beta, 23: 22,25-$ diepoxy-23,24-dihydroxy-9,19-cyclolanostan-3 $\beta$-yl a-L-arabinopyranoside (Watanabe et al., 2002). Actaea podocarpa which is also known as Cimicifuga americana (Summer cohosh) led to the isolation of cyclolanostane type glycosides named podocarpasides (A-G) that was reported by Z.Ali et al. (2007).
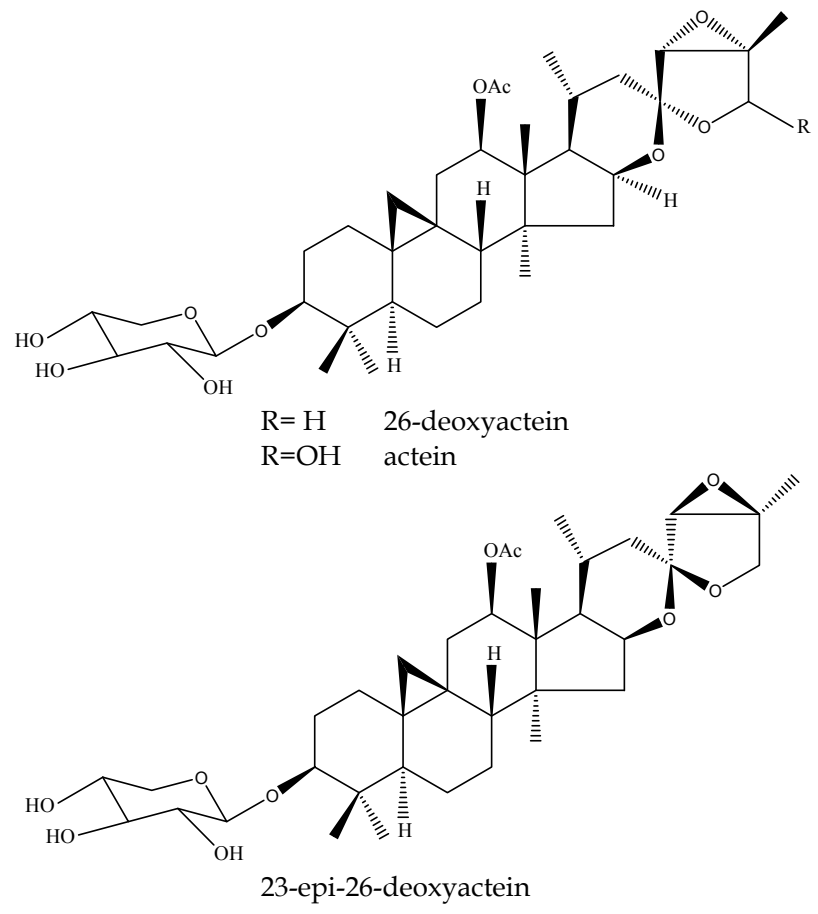

\subsubsection{Tetraterpenoids}

Members of this class also called as carotenes or carotenoids because of their occurrence in the carrot (Daucus carota). Carotenoids are naturally occurring pigments and they are responsible for the yellow, orange, red and purple colors of plants as well as bacteria and algae (Robbers et al., 1996; Heinrich et al., 2004). Fruits and vegetables are rich sources of carotenoids and it has been revealed that carotenoids are strong antioxidant compounds for the prevention of cancer and other human diseases (Burns et al., 2003). Numerous epidemiological studies have demonstrated that carotenoids may be responsible for the beneficial effects associated with the intake of green and yellow vegetables and fruits for cancer prevention in humans. It has been 
become clear that not only $\beta$-carotene but also $\alpha$-carotene and lycopene, some xanthophylls such as lutein, canthaxanthin, fucoxanthin, halocynthiaxanthin, etc. possess significant cancer chemopreventive effects (Maoka et al., 2001).

The carotenoids can be divided into two groups. Hydrocarbons, soluble in petroleum ether is the first group, orange-red carotenoids $a, \beta, \gamma$-carotene, red-carotenoid lycopene are typical samples of hydrocarbon carotenoids. The second group called as xanthophylls which mainly contains oxygenated derivatives (alcohols, aldehydes, ketones, epoxides and acids) such as lutein, crytoxanthin, rhodoxanthin, violaxanthin, crocetin and ext. are soluble in ethanol (Ikan, 1991).

General isolation procedure of carotenoids was described by Kimura \& Rodriguez-Amaya (2002) using column chromatography. Carotenoids are widely distributed in leafy vegetables; therefore they are providing good sources for isolation. Cold acetone exctract was prepared from lettuce, partitioned to petroleum ether, and then concentrated under vacuum to obtain crude extract. The crude extract was separated on MgO-Hyflosupercel (1:1 activated for $2 \mathrm{~h}$ at $110{ }^{\circ} \mathrm{C}$ ) column chromatography using ether-petroleum ether $(8 \%)$ and acetone-petroleum ether $(10-15 \%, 15-18 \%, 25-40,60-70 \%)$ as mobile phase to yield $\beta$-carotene, lactucaxanthin, violaxanthin, lutein, neoxanthin, chlorophylls respectively. All fractions eluted with petroleum ether containing acetone were washed four or three times with water in a separatory funnel to remove the acetone and then dried with $\mathrm{Na}_{2} \mathrm{SO}_{4}$. This method allows to efficiently and quickly separation of carotenoids (Kimure \& Rodriguez-Amaya, 2002).

Lycopene, known as tomato pigment, is widely distributed in nature. It was isolated from Tamus communis firstly. Lycopene can be extracted from tomato paste with $\mathrm{MeOH}-\mathrm{CH}_{2} \mathrm{Cl}_{2}$ mixture after dehydration of tomato paste by $\mathrm{MeOH}$. The extract was concentrated, and then crystallized twice from benzene by the addition of $\mathrm{MeOH}$ to obtain lycopene of 98 to $99 \%$ purity. Further purification can be achieved by column chromatography on calcium hydroxide (Ikan, 1997).<smiles>CC(C)=CC=CC(C)=CC=CC=C(C)C=CC=C(C)C=CC=C(C)CCC=C(C)C</smiles>

lycopene

Palm oil contains carotenoids. Palm oil mill effluent that is remaining part of the palm oil industry was extracted with hexane. Hexane extract was evaporated and then subjected to column chromatography on silica gel. Elution was performed by hexane to obtain $\beta$ carotene successively. The best separation procedure was performed with the 1:6 ratio of extracted oil: silica gel and the $40{ }^{\circ} \mathrm{C}$ temperature (Ahmad et al., 2009).<smiles>CC1=C(/C=C/C(C)=C/C=C/C(C)=C/C=C/C=C(C)/C=C/C=C(C)/C=C/C2=C(C)CCCC2(C)C)C(C)(C)CCC1</smiles>

$\beta$-carotene 
Ripe fruits of paprika (red pepper), which are used widely as vegetables and food colorants, are good source of carotenoid pigments. The red carotenoids in paprika (Capsicum annuum L.) are mainly capsanthin, capsorubin and capsanthin 3,6-epoxide (Maoka et al., 2001). The methanol $(\mathrm{MeOH})$ extract of the fruits of $C$. annuum L. was partitioned between $n$-hexane$\mathrm{Et}_{2} \mathrm{O}(1: 1)$ and $10 \%$ aqueous $\mathrm{NaCl}$. The organic layer was concentrated to dryness. The residue was subjected to silica gel column chromatography using hexane, hexane-ether $(8: 2)$, hexane-ether (7:3), hexane-ether (5:5), ether, ether-acetone (2:8), ether-acetone (5:5) and acetone, successively. Each fraction was further purified by HPLC on a $\mathrm{C}_{18}$ reversed phase column with $\mathrm{CH}_{2} \mathrm{Cl}_{2}-\mathrm{CH}_{3} \mathrm{CN}(2: 8)$ as the eluent. Capsanthin obtained from fractions eluted with ether-acetone (5:5) from silica gel column, Capsanthin 3'-ester from eluted with hexaneether (1:1) from silica gel column, Capsanthin 3,3'-diester eluted with hexane-ether (8:2) from silica gel column; Capsorubin eluted with ether-acetone (2:8) from silica gel column, Capsorubin 3,3'-diester eluted with hexane-ether (7:3) from silica gel column. Capsanthin 3,6-epoxide eluted with ether-acetone (2:8) from silica gel column. Cucurbitaxanthin A 3'ester eluted with ether-hexane (3:7) from silica gel column (Maoka et al., 2001). Latoxanthin, a minor carotenoid was isolated from the fruits of Capsicum annuum var. lycopersiciforme flavum, yellow paprika. Exract of the yellow paprika was subjected to column chromatography and eluted with hexane-acetone mixture (3:7). Repeated chromatography on $\mathrm{CaCO}_{3}$ column and then crystallization in benzene-hexane led to the isolation of latoxanthin as red crystals (Nagy et al., 2007).

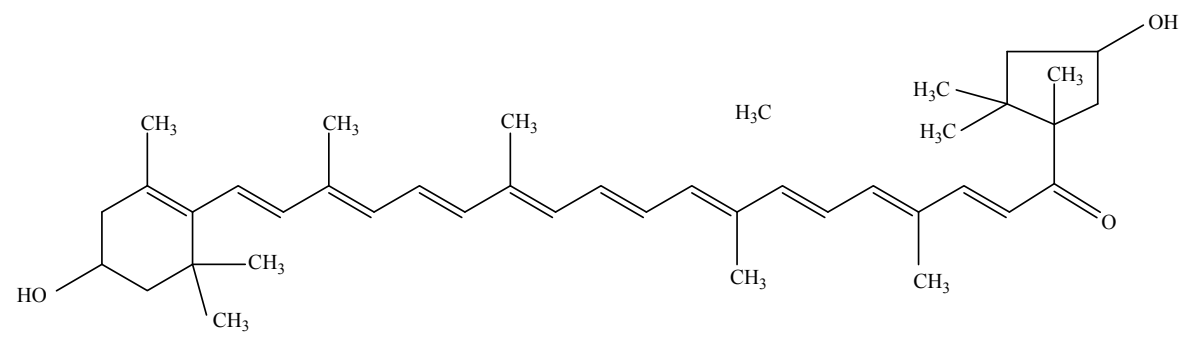

Capsanthin

\subsection{Flavonoids}

Flavonoids are one of the largest groups of secondary metabolites and widely distributed in leaves, seeds, bark and flowers of plants with more than 4000 different structures which are classified according to their chemical structures as follows; flavones, flavonols, flavanones, dihydroflavonols, isoflavones, anthocyanins, catechins and calchones. Flavonoids which are part of human diet are thought to have positive effects on human health such as reducing risk of cardiovascular diseases and cancer. Most of the beneficial effects of flavonoids are attributed to their antioxidant and chelating abilities (Cook \& Samman, 1996; Peterson \& Dwyer, 1998; Heim et al., 2002; Rijke et al., 2006). Flavonoids are structurally related compounds with a chromane-type skeleton with a phenyl substituent in the $\mathrm{C}_{2}$ or $\mathrm{C}_{3}$ position (Rijke et al., 2006). They are consisting of phenylpropane $\left(\mathrm{C}_{6}-\mathrm{C}_{3}\right)$ unit derived from shikimic acid pathway and $\mathrm{C}_{6}$ unit derived from polyketide pathway biosynthetically (Heinrich et al., 2004).

Flavonoids are present generally as mixtures and it is very rare to find only one single flavonoid components in plants (Harborne, 1998). They are phenolic compounds and 
hydroxyl groups often located at positions $3,5,7,3^{\prime}, 4^{\prime}$ and/or $5^{\prime}$. One or more of these hydroxyl groups are frequently methylated, acetylated, prenylated or sulphated. Flavonoids are present in plants as aglycone or as their glycosides generally (Rijke et al., 2006).

Extraction of the flavonoids can be performed with solvents that are chosen according to their polarity. Less polar aglycones such as isoflavones, flavanones, dihydroflavonols, higly methylated flavones and flavonols can be extracted with $\mathrm{CH}_{2} \mathrm{Cl}_{2}, \mathrm{CHCl}_{3}$, ether, EtOAC. However the more polar aglycones including hydroxylated flavones, flavonols, chalcones and flavonoid glycosides are generally extracted by polar solvents such as acetone, alcohol, water and their combinations (Harborne, 1975; 1998). Many different chromatographic techniques are employed for flavonoids isolation among them column chromatography remains the most useful technique for large scale isolation procedure. Conventional opencolumn chromatography is still widely used because of its simplicity and its value as an initial separation step. Preparative work on large quantities of flavonoids from crude plant extracts is also possible. Silica gel, polyamide, sephadex, cellulose are commonly used adsorbents. Silica gel is recommended mainly for separation of less polar flavonoids (isoflavones, flavanones, dihydroflavonols and highly methylated/acetylated flavones and flavonols). However, some flavonoid glycosides also can be purified on silica gel using more polar solvents as eluants. Cellulose can be considered as a saceld-up form of paper chromatography. Cellulose is suitable for separation of all class of flavonoids and their glycosides. However, cellulose has low capacity and limited resolving power. Sephadex led to the isolation of compounds on the basis of their molecular size. The hydroxypropylated dextran gel, Sephadex LH-20 is designed for use of with organic solvents or water/solvent mixtures. For Sephadex gels, as well as size exclusion, adsorption and partition mechanisms operate in the presence of organic solvents. Although methanol and ethanol can be used as eluents for proanthocyanidins, acetone is better for displacing the high molecular weight polyphenols. Slow flow rates are also recommended. Open-column chromatography with certain supports (silica gel, polyamide) suffers from a certain degree of irreversible adsorption of the solute on the column. Modifications of the method such as dry-column chromatography, vacuum liquid chromatography are also provide practical usage for the rapid fractionation of plant extracts. VLC with a polyamide support has been reported for succesive separation of flavonol glycosides. Medium-pressure liquid chromatography<smiles>O=C1c2ccccc2OC(c2ccccc2)C1(c1ccccc1)c1ccccc1O</smiles>

flavone

flavonol

flavonone dihydroflavonol<smiles>O=C(/C=C/c1ccccc1)c1ccccc1</smiles> 
(MPLC) which is a closed column (generally glass) connected to a compressed air source or a reciprocating pump covers is also a simple alternative method to open-column chromatography or flash chromatography, with both higher resolution and shorter separation times. MPLC columns have a high loading capacity, up to a 1:25 sample-topacking-material ratio, and are ideal for the separation of flavonoids. In MPLC, the columns are generally filled by the user. Particle sizes of 25 to $200 \mu \mathrm{m}$ are usually advocated (15 to 25 , 25 to 40 , or 43 to $60 \mu \mathrm{m}$ are the most common ranges) and both slurry packing and dry packing is possible. When compared a shorter column of larger internal diameter with a long column of small internal diameter (with the same amount of stationary phase) resolution is increased. Choice of solvent systems can be efficiently performed by TLC or by analytical HPLC (Harborne, 1975; 1998; Andersen \& Markham, 2006).

Vitex agnus-castus (Verbenaceae), (Chasteberry or chaste-tree), is used for the treatment of management of female reproductive disorders including premenstrual problems (PMS), menopausal symptoms, and insufficient milk production. The German Commission E recommends it for menstrual problems, mastalgia, and premenstrual syndrome. The specific chemical components responsible for its clinical effects have not been determined but some iridoids, terpenoids as well as flavonoids have been isolated from the leaves or fruits (Hirobe et al., 1997; Hadju et al., 2007). Hirobe et al. (1997) was described the isolation of luteolin, artemetin, isorhamnetin, 4', 5-dihyroxy-3, 3', 6, 7-tetramethoxyflavone as well as four luteolin caffeoylglucoides. Fruits of the chasteberry were powdered and extracted with $\mathrm{MeOH}$. The concentrated extract was partitioned between $\mathrm{H}_{2} \mathrm{O}$ and hexane, $\mathrm{CHCl}_{3}, \mathrm{BuOH}$ respectively. $\mathrm{BuOH}$ fraction was subjected to $\mathrm{HP}-20$ column chromatography and eluted with $\mathrm{H}_{2} \mathrm{O}, 40 \%$, $60 \%$ and $80 \% \mathrm{MeOH}$ respectively to yield five fractions (Fr. A-E). Fr. D was subjected to further separation on Sephadex LH-20 and then silica gel column chromatography and elution was performed by $\mathrm{CHCl}_{3}-\mathrm{MeOH}(1: 1)$ and $\mathrm{CHCl}_{3}-\mathrm{MeOH}-\mathrm{H}_{2} \mathrm{O}$ (8:9:1-6.7:3:0.3) succesively. Further purification was performed by means of ODS MPLC and HPLC with $\mathrm{MeOH}-\mathrm{H}_{2} \mathrm{O}$ and $\mathrm{ACN}-\mathrm{H}_{2} \mathrm{O}$ to obtain luteolin 6-C-(4"'-methyl-6"'-O-trans-caffeoylglucoide), luteolin 6-C-(6"'-Otrans-caffeoylglucoide), luteolin 6-C-(2"-O-trans-caffeoylglucoide) and luteolin 7-O-(6"'-pbenzoylglucoide), luteolin and isorhamnetin. To obtain 4', 5-dihyroxy-3, 3', 6, 7tetramethoxyflavone and artemetin hexane extract was subjected to column chromatography and eluted with hexane-EtOAc (10:0-0:10) followed with EtOAc-MeOH (1:1). The EtOAc$\mathrm{MeOH}(1: 1)$ eluate was subsequently separated using ODS MPLC and finally purified by means of ODS HPLC elution with $80 \% \mathrm{MeOH}$ (Hirobe et al., 1997).

Dried and powdered flowering stems of $V$. agnus castus were extracted with $\mathrm{MeOH}$ and extracts were evaporated under reduced pressure to yield syrupy residue. The $\mathrm{MeOH}$ extract was dissolved in $\mathrm{H}_{2} \mathrm{O}$ and partitioned with $\mathrm{CHCl}_{3}$ followed by $\mathrm{BuOH}$. A part of the $\mathrm{BuOH}$ phase was fractionated on a silica gel column eluting with a gradient solvent system $\left(\mathrm{CHCl}_{3}-\mathrm{MeOH}\right)$ to give nine main fractions (Frs. A-I). Fraction $\mathrm{G}$ was further chromatographed over silica gel column eluting with EtOAc-MeOH- $\mathrm{H}_{2} \mathrm{O}$ (100:5:2 to 100:17:13) to yield eight fractions (Frs. G1-8). Fr G6 was applied to repeated column chromatographies (CC) over Sephadex LH-20 eluted with $\mathrm{MeOH}$ to afford isoorientin (Luteolin 6-C-glucoside) and luteolin 7-O-glucoside. Fr. G2 was subjected to column chromatography on Sephadex $\mathrm{LH}-20$ using $\mathrm{MeOH}$ to give compound (2"-O-transcaffeoylisoorientin. Fractionation of Fr. F by open CC on silica gel using EtOAc- $\mathrm{MeOH}-\mathrm{H}_{2} \mathrm{O}$ (100:17:13) yielded subfractions F1-6 . Fr. F2 was submitted to Sephadex LH-20 CC (MeOH) to afford pure 6"-O-transcaffeoylisoorientin (Kuruüzüm-Uz et al., 2008). 


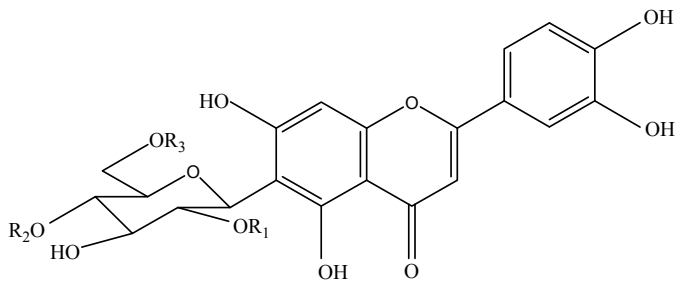

$\mathrm{R}_{1}=\mathrm{H}, \mathrm{R}_{2}=\mathrm{CH}_{3}, \mathrm{R}_{3}=$ trans caffeoyl

luteolin 6-C-(4"'-methyl-6" $-O$-trans-caffeoylglucoide)

$\mathrm{R}_{1}=\mathrm{R}_{2}=\mathrm{H}, \mathrm{R}_{3}=$ trans caffeoyl luteolin 6-C-(6" $-O$-trans-caffeoylglucoide $)$

$\mathrm{R}_{1}=$ trans caffeoyl, $\mathrm{R}_{2}=\mathrm{R}_{3}=\mathrm{H}$ luteolin 6-C-(2"'-O-trans-caffeoylglucoide)<smiles>[R3]c1ccc(-c2oc3cc([R])c([R])c([B])c3c(=O)c2[R3])cc1[R9]</smiles>

$\mathrm{R}_{1}=\mathrm{O}-\mathrm{Glc}\left(6^{\prime \prime}-\mathrm{p}\right.$-hydroxybenzoyl) $\mathrm{R}_{2}=\mathrm{R}_{4}=\mathrm{H}, \mathrm{R}_{3}=\mathrm{R}_{5}=\mathrm{R}_{6}=\mathrm{OH}$

$\mathrm{R}_{1}=\mathrm{R}_{2}=\mathrm{R}_{4}=\mathrm{R}_{5}=\mathrm{OCH}_{3}, \mathrm{R}_{3}=\mathrm{R}_{6}=\mathrm{OH}$

$\mathrm{R}_{1}=\mathrm{R}_{3}=\mathrm{R}_{5}=\mathrm{R}_{6}=\mathrm{OH}, \mathrm{R}_{2}=\mathrm{R}_{4}=\mathrm{H}$

$\mathrm{R}_{1}=\mathrm{R}_{2}=\mathrm{R}_{4}=\mathrm{R}_{5}=\mathrm{R}_{6}=\mathrm{OCH}_{3}, \mathrm{R}_{3}=\mathrm{OH}$

$\mathrm{R}_{1}=\mathrm{R}_{3}=\mathrm{R}_{4}=\mathrm{R}_{6}=\mathrm{OH}, \mathrm{R}_{5}=\mathrm{OCH}_{3}, \mathrm{R}_{2}=\mathrm{H}$ luteolin 7-O-(6"'-p-benzoylglucoide) $4^{\prime}$, 5-dihyroxy-3, 3', 6, 7tetramethoxyflavone luteolin artemetin isorhamnetin<smiles>O=c1cc(-c2ccc(O)c(O)c2)oc2cc(O)c(C3OC(O)C(O)C(O)C3O)c(O)c12</smiles>

isoorientin<smiles></smiles>

lutelin-7-glycoside

Isoflavonoids such as puerarin, daidzin and daidzein was isolated from Pueraria lobata (Willd) Ohwi roots. Pueraria roots are used in Chinese traditional medicine with "gegen" names for common cold. Daidzein, also known as soya isoflavon has spazmolytic activity. Pueraria roots were extracted with acetone to separate non-glycosidic flavonoids. Acetone extract was separated on silica gel column chromatography using hexane-EtOAc mixture to obtain daidzein, formononetin and puerarol. The residue was extracted against $\mathrm{MeOH}$ and then concentrated to dryness under vacuum. To obtain crude extract were dissolved in $\mathrm{H}_{2} \mathrm{O}$ and extracted with $\mathrm{BuOH}$ to separate glycosidic compounds which were further fractitioned chromatographically on Sephadex LH-20 eluting with $\mathrm{MeOH}$. The glycosidic mixture was chromatographed over silica gel column using $\mathrm{CHCl}_{3}-\mathrm{MeOH}-\mathrm{H}_{2} \mathrm{O}$ (40:16:3) to separate puerarin, daidzin and other glycosides mixtures. Further purification of glycosides mixture was performed by HPLC (Ohshima et al., 1987). 


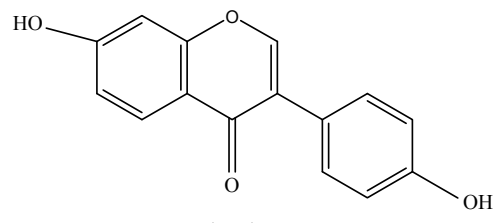

daidzein

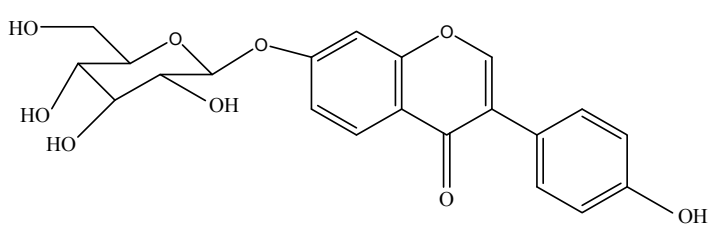

daidzin

Crataegus species (Hawthorn), (Rosaceae) is a traditional medicinal plant that possess beneficial effects on the heart and blood circulation. Crataegus monogyna and C. laevigata are the most often used species. Dried flowers, leaves and fruits are mainly used for mild to moderately severe heart failure and coronary heart diseases. Oligomeric procyanidins and ()-epicatechin as well as flavonoids are known as the main active constituents (Svedström et al., 2002; Sözer et al., 2006). C. laevigata flowers and leaves methanolic water extract led to the isolation of procyanidins. Methanolic-water extract was prepared in an ultrasonic bath and then extract was concentrated to a smaller volume under vacuum. Concentrated extract was partitioned with petroleum ether and EtOAc respectively. The EtOAc soluble part evapoarated to the dryness and subjected to column chromatography on polyamide CC 6 column eluting with $\mathrm{MeOH}, \mathrm{MeOH}-\mathrm{H}_{2} \mathrm{O}(7: 3)$ and $\mathrm{Et}_{2} \mathrm{O}-\mathrm{H}_{2} \mathrm{O}$ (7:3). Fractions 18-33 allow the isolation of (-)-epicatechin after purification by preparative HPTLC. Epicatechin dimmers; epicatechin- $(4 \beta \rightarrow 8)$-epicatechin (procyanidin B-2); catechin-(4a $\rightarrow 8)$-epicatechin (procyanidin B-4); epicatechin-( $4 \beta \rightarrow 6)$-epicatechin (procyanidin B-5) were obtained from the 43-75 and 117-121 fractions by column chromatography on Sephadex LH-20 uaing EtOH as eluents. Fractions 123-140 was separated with EtOH on Sephadex LH-20 to yield procyanidin trimers, epicatechin- $(4 \beta \rightarrow 8)$-epicatechin- $(4 \beta \rightarrow 8)$-epicatechin (procyanidin $C-1$ ); epicatechin- $(4 \beta \rightarrow 6)$-epicatechin- $(4 \beta \rightarrow 8)$-epicatechin and tetramer epicatechin- $(4 \beta \rightarrow 8)$ epicatechin- $(4 \beta \rightarrow 8)$-epicatechin- $(4 \beta \rightarrow 8)$-epicatechin (procyanidin D-1) (Svedström et al., 2002). Many flavonoids such as hyperoside, rutin, and quercetin have also been isolated from Crataegus species. The dried and powdered leaves of Crategus davisii were extracted with petroleum ether and then with $\mathrm{EtOH}$. The petroleum ether extract was concentrated and extracted with $60 \% \mathrm{EtOH}$. The aqueous extract was concentrated and extracted with $\mathrm{CHCl}_{3}$ (Extract A). The EtOH extract was concentrated and extracted with toluene, $\mathrm{CHCl}_{3}$ (Extract B) and EtOAc (Extract C) successively. Extract A was chromatographed first by vacuum liquid chromatography (VLC) on silica gel with Petroleum ether- $\mathrm{CHCl}_{3}-\mathrm{MeOH}$ mixtures. Fractions 11-12 $\left(\mathrm{CHCl}_{3}-\mathrm{MeOH}\right.$ 80:20) were then chromatographed on a chromatotron (silica gel) again with $\mathrm{PE}-\mathrm{CHCl}_{3}-\mathrm{MeOH}$ mixtures and from fraction 42 (petroleum ether- $\mathrm{CHCl}_{3}, 20: 80$ ) crataequinone $\mathrm{B}$ were obtained. Extract $\mathrm{B}$ was chromatographed first by VLC on silica gel with toluene- $\mathrm{Et}_{2} \mathrm{O}-\mathrm{MeOH}$ mixtures. Fractions 68 (toluene- $\mathrm{Et}_{2} \mathrm{O}, 75: 25$ to $60: 40$ ) were then chromatographed on a chromatotron (silica gel) again with toluene- $\mathrm{Et}_{2} \mathrm{O}-\mathrm{MeOH}$ mixtures and from fractions 40-48 (toluene- $\mathrm{Et}_{2} \mathrm{O} 30: 70$ to 10:90 ) quercetin were obtained. Extract $C$ was chromatographed first on a silica gel column with toluene-EtOH mixtures. Main fractions 153-304 (toluene-EtOH, 50:50) were then chromatographed on a chromatotron (silica gel) with toluene- $\mathrm{CHCl}_{3}-\mathrm{EtOH}$ mixtures and from fractions 24-32 $\left(\mathrm{CHCl}_{3}-\mathrm{EtOH}, 50: 50\right.$ to 30:70) hyperoside, vitexin 4'-rhamnoside and rutin were obtained using preparative PC (acetic acid- $\mathrm{H}_{2} \mathrm{O}, 15: 85$ ). Main fractions 305-380 (EtOH) were chromatographed on a polyamide column with $\mathrm{H}_{2} \mathrm{O}-\mathrm{EtOH}$ mixtures and from fractions 77-133 ( $\left.\mathrm{H}_{2} \mathrm{O}-\mathrm{EtOH}, 80: 20\right)$ vitexin 2"'-rhamnoside was obtained (Sözer et al., 2006). Apigenin, hesperetin, eriodictyol, luteolin, quercetin, luteolin-7-O-glucoside, hyperoside, 
vitexin, vitexin-4'-O-rhamnoside were isolated from Crataegus microphylla C. Koch. by similar procedure (Melikoğlu et al., 2004).<smiles>O=c1c(O)c(-c2ccc(O)c(O)c2)oc2cc(O)cc(O)c12</smiles>

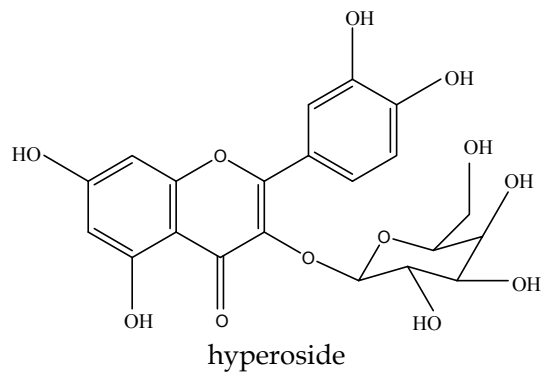

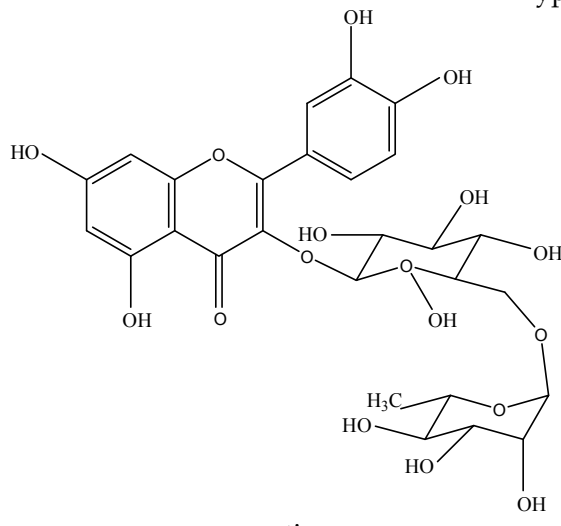

rutin

Cranberry (Vaccinium macrocarpon) fruits are excellent raw materials for juice production, as they contain numerous antioxidants including phenolic compounds, vitamin $\mathrm{C}$, minerals and many others. Compounds present in the fruits of the Vaccinium species are reported to play several roles in human health maintenance. Consumption of cranberries is found to have protective effects against urinary tract infections. Health benefits such as reduced risks of cancer and cardiovascular disease, are believed to be due to the presence of various polyphenolic compounds, including anthocyanins, flavonols, and procyanidins. The potent antioxidant properties of Vaccinium fruits have been well documented. Biological properties of the fruit extract, rich in anthocyanins, include antioxidant capacity, astringent and antiseptic properties, ability to decrease the permeability and fragility of capillaries, inhibition of platelet aggregation, inhibition of urinary tract infection and strengthening of collagen matrices via cross linkages. Cranberry extracts also exhibited a selective tumor cell growth inhibition in prostate, lung, cervical, colon, and leukemia cell lines (Caillet et al., 2011). To isolate cranberry phenolics, cranberry fruits were crushed, macerated with aqueous acetone $\left(80: 20\right.$ acetone- $\left.\mathrm{H}_{2} \mathrm{O}\right)$ and extracted at room temperature for with agitation. The resulting extract was filtered, extraction was repeated on the remaining solids, and the two aqueous acetone extracts were combined. The acetone was removed by rotary evaporation at $35{ }^{\circ} \mathrm{C}$ under high vacuum and frozen at $-20{ }^{\circ} \mathrm{C}$. The extracts were prepurified using a method described below After removal of acetone, the aqueous layer was partitioned into hexane to remove carotenoids, fats, and waxes, followed by additional 
partitioning into ethyl acetate to selectively extract proanthocyanidins with anthocyanin glycosides and flavonols. The ethyl acetate extract was concentrated by vacuum evaporation. The ethyl acetate extract was dissolved in a small amount of methanol for transfer to column chromatography system pre-packed with sephadex LH-20 (column size 100 $\times 45 \mathrm{~mm}$ ). The column was subsequently eluted with water, $20 \%$ methanol in water, $60 \%$ methanol in water, $100 \%$ methanol and $80 \%$ acetone in water. The water (first liter) eluate yielded organic acids, with subsequent $20 \%$ methanol in water elution of anthocyanins, which were pooled together on the basis of color and TLC. The fraction eluted with $60 \%$ methanol in water, methanol, and $80 \%$ acetone in water yielded the flavonol glycoside fraction, proanthocyanidin fraction. Further purification was performed using preparative HPLC to obtain myricetin-3- $\beta$-galactoside, myricetin-3- $\alpha$-arabinofuranoside, quercetin-3- $\beta$-galactoside, quercetin-3- $\beta$-glucoside, quercetin-3-rhamnopyranoside, quercetin-3- $O$-(6"- $p$-benzoyl)- $\beta$ galactoside and epicatechins (monomer, dimer and trimer) (Singh et al., 2009) .<smiles>Oc1cc(O)c2c(c1)OC(c1ccc(O)c(O)c1)C(O)C2</smiles>

epicatechin (monomer)<smiles></smiles>

myricetin-3-galactoside

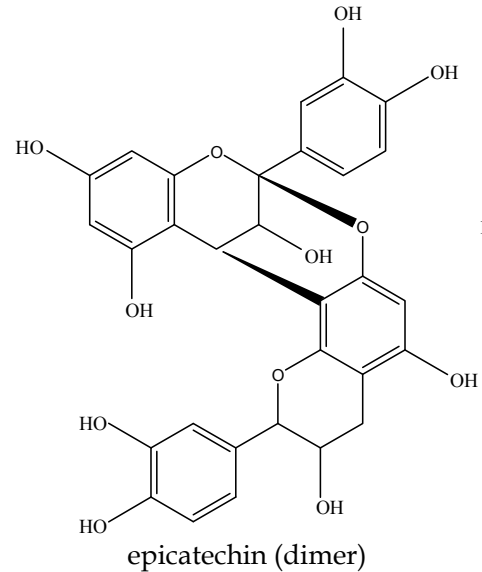

epicatechin (dimer)<smiles>O=c1c(OC2OC3C(CO)OC(C2O)C3O)c(-c2cc(O)c(O)c(O)c2)oc2cc(O)cc(O)c12</smiles>

myricetin-3-arabinofuranoside 


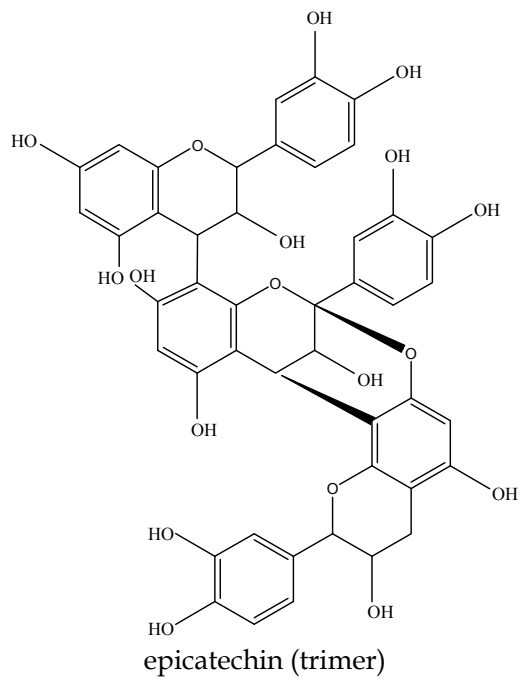

Resveratrol is known as 3, 5, 4'-trihydroxystilbene, is widely used in medicine and health products due to their important biological activities such as anti-inflammatory, anticancer, and cardioprotective. Resveratrol is not widely distributed in plants and has been reported that few fruits and vegatables contain. Polygonum cuspidatum (Polygonaceae) is one of the richest sources of resveratrol (Soleas et al., 1997; Mantegna et al., 2012). Resveratrol was isolated from Pleuropterus ciliinervis belonging to Polygonaceae (J.P.Lee et al., 2003). Dried roots of the plant were extracted with $\mathrm{MeOH}$. $\mathrm{MeOH}$ extract was evaporated to dryness and suspended in $\mathrm{H}_{2} \mathrm{O}$ and then partitioned with hexane, EtOAc, $\mathrm{BuOH}$, respectively. The EtOAc soluble fraction was subsequently fractionated on silica gel column chromatography and eluted with gradient of hexane-EtOAc (2-50\%) and EtOAc-MeOH (5:1) to yield six fractions. Fraction 4 rechromatographed on silica gel column using hexane-EtOAc gradient mixture to afford resveratrol (J.P.Lee et al., 2003). Gnetum gnemon Linn. (Gnetaceae) from Gnetum genus is known to contain abundant stilbene derivatives also led to the isolation of resveratrol. Successive extraction of acetone, $\mathrm{MeOH}$ and $70 \% \mathrm{MeOH}$ respectively was performed. The acetone extract was subjected to silica gel column chromatography using $\mathrm{CHCl}_{3}-\mathrm{MeOH}$ in increasing polarity as eluents to give eleven fractions. Fraction 1 gives resveratrol together with other stilbenes after column chromatography of Fraction 1 on Sephadex LH-20 (MeOH) (Iliya et al., 2003).

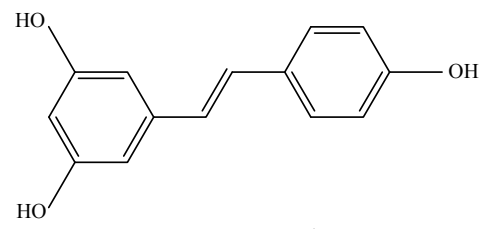

Resveratrol

\section{Conclusion}

Remarkable advances have been accomplished in natural products isolation since the discovery of chromatography. Natural products are present generally as mixtures which 
makes hard to separation of them. Different chromatographic techniques such as paper chromatography (PC), thin layer chromatography (TLC), gas liquid chromatography (GLC), high performance liquid chromatography and column chromatography employ for separation and purification of natural products. Amon them column chromatography which is the oldest chromatographic technique, is still widely used especially for large scale isolation procedure. Conventional open column chromatography is preferable because of its simlicity. Different stationary phases can be available according to the polarity of the test samples such as silica gel, bonded-phase silica gel, polyamide, sephadex, cellulose, ionexchange resins. However separation procedure in conventional column chromatography is time consuming and this method suffers from a certain degree of irreversible adsorption of the solute on the column. Vacuum liquid chromatography (VLC) a modified method of conventional column chromatograhy provides practical usage for the rapid fractionation of extracts. Medium-pressure liquid chromatography (MPLC) a closed column which connected to a compressed air source or a reciprocating pump covers is also a simple alternative method to open-column chromatography or flash chromatography.

\section{References}

Abdelgaleil, S.A.M.; Abbassy, M.A.; Belal, A.H. \& Abdel Rasoul, M.A.A. (2008). Bioactivity of Two Major Constituents Isolated from The Essential Oil of Artemisia judaica L. Bioresource Technology, Vol. ,pp. 5947-5950.

Ahmad, A.L.; Chan, C.Y.; Abd Shukor, S.R.; Mashitah, M.D. \& Sunarti, A.R. (2009). Isolation of Carotenes from Palm Oil Mill Effluent and Its Use as a Source of Carotenes. Desalination and Water Treatment, Vol. 7, pp. 251-256.

Ali, S.M.; Saleem, M.; Ahmad, W.; Parvez, M.; \& Yamdagni, R. (2002). A Chlorinated Monoterpene Ketone, Acylated $\beta$-sitosterol Glycosides and a Flavanone Glycoside from Mentha longifolia (Lamiaceae). Phytochemistry, Vol. 59, pp. 889-895.

Ali, Z.; Khan, S.I.; Fronczek, F.R. \& Khan, I.A. (2007). 9,10-seco-9,19-Cyclolanostane Arabinosides from The Roots of Actaea podocarpa. Phytochemistry, Vol. 68, pp. 373382.

Balunas, M.J. \& Kinghorn, A.D. (2005). Drug Discovery from Medicinal Plants. Life Sciences, Vol. 78, pp. 431-441.

Beek, T.A. \& Lelyveld, G.P. (1997). Preparative Isolation and Separation Procedure for Ginkgolides A, B, C, and J and Bilobalide. Journal of Natural Products, Vol. 60, pp. 735-738.

Bhat, S.V., Nagasampagi, B.A., \& Sivakumar, M. (2005). Chemistry of Natural Products. Narosa Publishing House, India.

Borelli, F. \& Ernst, E. (2008). Black cohosh (Cimicifuga racemosa) for Menopausal Symptoms: A Systematic Review of Its Efficacy. Pharmacological Research, Vol. 58, pp. 8-14.

Bos, R.; Hendriks, H.; Bruins, A.P.; Kloosterman, J. \& Sipma, G. (1986) Isolation and Identification of Valerenane Sesquiterpenoids from Valeriana officinalis. Phytochemistry, Vol. 25, pp. 133-135.

Briskin, D.P. (2000). Medicinal Plants and Phytomedicines. Linking Plant Biochemistry and Physiology to Human Health. Plant Physiology, Vol. 124, pp. 507-514.

Brown, G.D.; Liang, G.Y. \& Sy, L.K. (2003). Terpenoids from the Seeds of Artemisia annua. Phytochemistry, Vol. 64, pp. 303-323. 
Burns, J.; Fraser, P.D. \& Bramley, P.M. (2003). Identification and Quantification of Carotenoids, Tocopherols and Chlorophylls in Commonly Consumed Fruits and Vegetables. Phytochemistry, Vol. 62, pp. 939-947.

Caillet, S.; Cote, J.; Doyon, G.; Sylvain, J.F. \& Lacroix, M. (2011). Effect of Juice Processing on the Cancer Chemopreventive Effect of Cranberry. Food Research International, Vol. 44, pp. 902-910.

Chen, S.N.; Li, W.; Fabricant, D.S.; Santarsiero, B.D.; Mesecar, A.; Fitzloff, J.F.; Fong, H.H.S.; \& Farnsworth, N.R. (2002). Isolation, Structure Elucidation, and Absolute Configuration of 26-Deoxyactein from Cimicifuga racemosa and Clarification of Nomenclature Associated with 27-Deoxyactein. Journal of Natural Products, 65, 601605.

Cheng, C.R.; Yue, Q.X.; Wu, Z.Y.; Song, X.Y.; Tao, S.J.; Wu, X.H.; Xu, P.P.; Liu, X.; Guan, S.H. \& Guo, D.A. (2010). Cytotoxic Triterpenoids from Ganoderma lucidum. Phytochemistry, Vol. 71, pp. 1579-1585.

Chin, Y.; Balunas, M.J.; Chai, H.B. \& Kinghorn, A.D. (2006). Drug Discovery from Natural Sources. The AAPS Journal, Vol. 8, pp. 239-253.

Cook, N.C. \& Samman, S. (1996). Flavonoids-Chemistry, metabolism, cardioprotective effects, and dietary sources. Nutritional Biochemistry, Vol. 7, pp. 66-76.

Dewick, P.M. (2009). Medicinal Natural Products (Third Edition), John Wiley \& Sons Ltd, England.

Fischer, N.H.; Isman, M.B. \& Stafford, H.A. (1991). Recent Advances in Phytochemistry Vol. 25, Modern Phytochemical Methods, Plenum Press, New York, United States of America.

Fu, H.; Zhang, L.; Yi, T.; Feng, Y. \& Tian, J. (2010). Two New Guaiane-Type Sesquiterpenoids from The Fruits of Daucus carota L. Fitoterapia, Vol. 81, pp. 443446.

Fukuda, N.; Tanaka, H. \& Shoyama, Y. (2000). Isolation of The Pharmacologically Active Saponin Ginsenoside Rb1 from Ginseng by Immunoaffinity Column Chromatography. Journal of Natural Products, Vol. 63, pp. 283-285.

Garg, S.N. \& Mehta, V.K. (1998). Acyclic Monoterpenes from The Essential Oil of Tagetes minuta Flowers. Phytochemistry, Vol. 48, pp. 395-396.

Garg, S.N.; Charles, R. \& Kumar, S. (1999). A New Acyclic Monoterpene Glucoside from the Capitula of Tagetes patula. Fitoterapia, Vol. 70, 472-474.

Gill, N.S. \& Bali, M. (2011). Isolation of Anti Ulcer Cucurbitane Type Triterpenoid from the Seeds of Cucurbito pepo. Research Journal of Phytochemistry, Vol. 5, pp. 70-79.

Giroud, C.; Felber, F.; Augsburger, M.; Horisberger, B.; Rivier, L. \& Mangin, P. (2000). Salvia divinorum: An Hallucinpgenic Mint Which Might Become a New Recreational Drug in Switzerland. Forensic Science International, Vol. 112, pp. 143-150.

Gould, M.N. (1997). Cancer Chemoprevention and Theraphy by Monoterpenes. Environmental Health Perspectives, Vol. 105, pp. 977-979.

Gunawardena, K.; Rivera, S.B. \& Epstein, W.W. (2002). The Monoterpenes of Artemisia tridentata ssp. vaseyana, Artemisia cana ssp. viscidula, Artemisia tridentata ssp.spiciformis. Phytochemistry, Vol. 59, pp. 197-203.

Hadju, Z.; Hohman, J.; Forgo, P.; Martinek, T.; Dervarics, M.; Zupko, I.; Falkay, G.; Cossuta, D. \& Mathe I. (2007). Diterpenoids and Flavonoids from the Fruits of Vitex agnuscastus and Antioxidant Activity of the Fruit Extracts and Their Constituents. Phytotheraphy Research, Vol. 21, pp. 391-394. 
Hamburger, M.; Adler, S.; Baumann, D.; Förg, A. \& Weinreich, B. (2003). Preparative Purification of the Major Anti-inflammatory Triterpenoid Esters from Marigold (Calendula officinalis). Fitoterapia, Vol. 74, pp. 328-338.

Hanson, J.R. (2003). Natural Products the Secondary Metabolites. The Royal Society of Chemistry, 1-27, Cambridge, UK.

Harborne, J.B.; Mabry, T.J. \& Mabry, H. (1975). The Flavonoids. Chapman and Hall Ltd., London, Great Britain.

Harborne, J.B. (1998). Phytochemical Methods; A guide to Modern Techniques of Plant Analysis,Chapman and Hall Ltd., London, Great Britain.

Heim, K.E.; Tagliaferro, A.R. \& Bobilya, D.J. (2002). Flavonoid Antioxidants: Chemistry, Metabolism and Structure-Activity Relationships. Journal of Nutritional Biochemistry, Vol. 13. pp. 572-584.

Heinrich, M.; Barnes, J.; Gibbons, S. \& Williamson, E.M. (2004). Fundamentals of Pharmacognosy and Phytotherapy. Churchill Livingstone, Spain.

Hirobe, C.; Qiao, Z.S.; Takeya, K. \& Itokawa, H. (1997). Cytotoxic Flavonoids from Vitex agnus-castus. Phytochemistry, Vol. 46, pp. 521-524.

Hossain, M.A. \& Ismail, Z. (2010). Isolation and Characterization of Triterpenes from the Leaves of Orthosiphon stamineus. Arabian Journal of Chemistry, 2010, in press.

Hong, C.H.; Kim, Y. \& Lee, S.K. (2001). Sesquiterpenoids from the Rhizome of Curcuma zedoaria. Archives of Pharmacal Research, Vol. 24, pp. 424-426.

Iliya, I.; Ali, Z.; Tanaka, T.; Linuma, M.; Furusawa, M.; Nakaya, K.; Murata, J.; Darnaedi, D.; Matsuura, N. \& Ubukata, M. (2003). Stilbene Derivatives from Gnetum gnemon Linn. Phytochemistry, Vol. 62, pp. 601-606.

Ikan, R. (1991). Natural Produtcs A Laboratory Guide (Second Edition), Academic Press, California, United States of America, 1991.

Jacobs, B.P. \& Browner, W.S. (2000). Ginkgo biloba: A Living Fossil. American Journal of Medicine, Vol. 108, 341-342.

Jaracz, S.; Malik, S. \& Nakanishi, K. (2004). Isolation of Ginkgolides A, B, C, J and Bilobalide from G. Biloba Extracts. Phytochemistry, Vol. 65, pp. 2897-2902.

Kimura, M. \& Rodriguez-Amaya, D.B. (2002). A Scheme for Obtaining Standards and HPLC Quantification of Leafy Vegetable Carotenoids. Food Chemistry, Vol. 78, pp. 389-398.

Klayman, D.L.; Lin, A.; Acton, N.; Scovill, J.P.; Hoch, J.M.; Milhous, W.K. \& Theoharides, A.D. (1984). Isolation of Artemisinin (Qinghaosu) from Artemisia annua Growing in the United States. Journal of Natural Produtcs, Vol. 47, pp. 715-717.

Kuruüzüm-Uz, A.; Güvenalp, Z.; Ströch, K.; Demirezer, Ö. \& Zeeck, A. (2008). Antioxidant Potency of Flavonoids from Vitex agnus-castus L. growing in Turkey. FABAD Journal of Pharmaceutical Sciences, Vol. 33, pp. 11-16.

Lee, D.Y.W.; Ma, Z.; Liu-Chen, L.Y.; Wang, Y.; Chen, Y.; Carlezon, W.A. \& Cohen, B. (2005). New Neoclerodane Diterpenoids Isolated from the Leaves of Salvia divinorum and their Binding Affinities for Human $\mathrm{k}$ Opioid Receptor. Bioorganic \& Medicinal Chemistry, Vol.13, pp. 5635-5639.

Lee, J.P.; Min, B.S.; An, R.B.; Na, M.K.; Lee, S.M.; Lee, H.K.; Kim, J.G.; Bae, K.H. \& Kang, S.S. (2003). Stilbenes from the Roots of Pleuropterus ciliinervis and their Antioxidant Activities. Phytochemistry, Vol. 64, pp. 759-763. 
Li, J.X.; Liu, J.; He, C.C.; Yu, Z.Y.; Du, Y.; Kadota, S. \& Seto, H. (2007). Triterpenoids from Cimicifuga Rhizome, a Novel Class of Inhibitors on Bone Resorption and Ovariectomy-Induced Bone Loss. Maturitas, Vol. 58, pp. 59-69.

Li, Y.; Husbands, S.M.; Mahon, M.F.; Traynor, J.R. \& Rowan, M.G. (2007). Isolation and Chemical Modification of Clerodane Diterpenoids from Salvia species as Potential Agonists at the kappa-opioid Receptor. Chemistry \& Biodiversity, Vol. 4, pp. 1586-93.

Liu, J. (1995). Pharmacology of Oleanolic Acid and Ursolic Acid. Journal of Ethnopharmacology, Vol. 49, pp. 57-68.

Liu, J. (2005). Oleanolic acid and Ursolic Acid: Research Perspectives. Journal of Ethnopharmacology, Vol. 100, pp. 92-94.

Lobo, R.; Prabhu, K.S. \& Shirwaikar, A. (2009). Curcuma zedoaria Rosc. (white turmeric): A Review of its Chemical, Pharmacological and Ethnomedicinal Properties. Journal of Pharmacy and Pharmacology, Vol. 61, pp. 13-21.

Mahmoud, A.A. \& Ahmed, A.A. (2006). A-Pinene-type Monoterpenes and Other Constituents from Artemisisa suksdorfi. Phytochemistry, Vol. 67, pp. 2103-2109.

Mantegna, S.; Binello, A.; Boffa, L.; Giorgis, M.; Cena, C. \& Cravotto, G. (2012). A One-pot Ultrasound-Assisted Water Extraction/Cyclodextrin Encapsulation of Resveratrol from Polygonum cuspidatum. Food Chemistry, Vol. 130, pp. 746-750.

Maoka, T.; Mochida, K.; Kozuka, M.; Ito, Y. Fujiwara Y, Hashimoto K, Enjo F, Ogata M, Nobukuni Y, Tokuda H, Nishino H. Cancer Chemopreventive Activity of Carotenoids in the Fruits of Red Paprika Capsicum annuum L. Cancer Letters, 2001, 172, 103-109.

Matsumura, T.; Ishikawa, T.; \& Kitajima, J. (2001). New p-menthanetriols and their Glucosides from the Fruit of Caraway. Tetrahedron, Vol. 57, pp. 8067-8074.

McCurdy, C.R. \& Scully, S.S. (2005). Analgesic substances derived from natural products (natureceuticals). Lice Sciences, Vol. 78, pp. 476-484.

McMurry, J. (2010). Organic Chemistry with Biological Applications. Brooks/Cole Cengage Learning,1015-1046. Canada.

Melikoğlu, G.; Bitiş, L. \& Meriçli, A.H. (2004). Flavonoids of Crataegus microphylla. Natural Product Research, Vol. 18, pp. 211-213.

Nagy, V.; Agocs, A.; Turcsi, E.; Molnar, P.; Szabo, Z. \& Deli, J. (2007). Latoxanthin, a Minor Carotenoid Isolated from the Fruits of Yellow Paprika (Capsicum annuum var. lycopersicum flavum). Tetrahedron Letters, Vol. 48, pp. 9012-9014.

Nhiem, N.X.; Tai, B.H.; Quang, T.H.; Kiem, P.V.; Minh, C.V.; Nam, N.H.; Kim, J.H.; Im, L.R.; Lee, Y.M. \& Kim, Y.H. (2011). A New Ursane-Type Triterpenoid Glycoside from Centella asiatica Leaves Modulates the Production of Nitric Oxide and Secretion of TNF-a in Activated RAW 264.7 Cells. Bioorganic \& Medicinal Chemistry, Vol. 21, pp. 1777-1781.

Ngo, K.S. \& Brown, G.D. (1998). Stilbenes, Monoterpenes, Diarylheptanoids, Labdanes and Chalcones from Alpinia katsumadai. Phytochemistry, Vol. 47, pp. 1117-1123.

Nian, Y.; Zhang, X.M.; Li, Y.; Wang, Y.Y.; Chen, J.C.; Lu, L. \& Zhou, L. (2011). Cycloartane Triterpenoids from the Aerial Parts of Cimicifuga foetida Linnaeus. Phytochemistry, Vol. 72, pp. 1473-1481.

Ninomiya, K.; Matsuda, H.; Shimoda, H.; Nishida, N.; Kasajima, N.; Yoshino, T.; Morikawa, T. \& Yoshikawa, M. (2004). Carnosic Acid, a New Class of Lipid Absorbtion Inhibitor from Sage. Bioorganic \& Medicinal Chemistry Letters, Vol. 14, pp. 1943-1946. 
Ohshimo, Y.; Okuyama, T.; Takahashi, K.; Takizawa, T. \& Shibata, S. (1988). Isolation and High Performance Liquid Chromatography (HPLC) of Isoflavonoids from the Pueraria Root. Planta Medica, Vol. 54, pp. 250-254.

Osorio, C.; Duque, C.; \& Fujimoto, Y. (2000). Oxygenated Monoterpenoids from Badea (Passiflora quadrangularis) Fruit Pulp. Phytochemistry, 53, 97-101.

Park, I.H.; Han, S.B.; Kim, J.M.; Piao, L.; Kwon, S.W.; Kim, N.Y.; Kang, T.L.; Park, M.K. \& Park, J.H. (2002). Four New Acetylated Ginsenosides from Processed Ginseng (Sun Ginseng). Archives of Pharmacological Research, Vol. 25, pp. 837-841.

Peterson, J. \& Dwyer, J. (1998). Flavonoids: Dietary Occurrence and Biochemical Activity. Nutrition Research, Vol. 18, pp 1995-2018.

Raaman, N. (2006). Phytochemical Techniques. New India Publishing Agency, New Delhi, India.

Rijke, E.; Out, P.; Niessen, W.M.A.; Ariese, F.; Gooijer, C. \& Brinkman, U.A.T. (2006). Analytical Separation and Detection Methods for Flavonoids. Journal of Chromatography A, Vol. 1112, pp. 31-63.

Rivero-Cruz, J.F.; Zhu, M.; Kinghorn, A.D. \& Wu, C.D. (2008). Antimicrobial Constituents of Thompson Seedless Raisins (Vitis vinifera) Against Selected Oral Pathogens. Phytochemistry Letters, Vol. 1, pp. 151-154.

Robbers, J.E.; Speedie, M.K. \& Tyler, V.E. (1996). Pharmacognosy and Pharmacobiotechnology. Williams \& Wilkins, Pennsylvania, United States of America.

Ruan, C.C.; Liu, Z.; Li, X.; Liu, X.; Wang, L.J.; Pan, H.Y.; Zheng, Y.N.; Sun, G.Z.; Zhang, Y.S. \& Zhang, L.X. (2010). Isolation and Characterization of a New Ginsenoside from the Fresh Root of Panax Ginseng. Molecules, Vol. 15, pp. 2319-2325, ISSN 1420-3049.

Sameeno, B. (2007). Chemistry of Natural Compounds. 10.09.2011. Available from: http://nsdl.niscair.res.in/bitstream/123456789/700/1/revised+terpenoids.pdf.

Sarker,SD.; Latif, Z. \& Gray AI. (2006). Natural Products Isolation (Second Edition), Humana Press, New Jersey, United States of America.

Senilh, V.; Bleckert, S.; Colin, M.; Guenard, D.; Picot, F.; Potier, P. \& Varenne, P. (1984) Journal of Natural Products, Vol. 47, pp. 131-137.

Schwaiger, S.; Zeller, I.; Pölzelbauer, P.; Frotschnig, S.; Laufer, G.; Messner, B.; Pieri, V.; Stuppner, H. \& Bernhard D. (2011). Identification and Pharmacological Characterization of the Anti-inflammatory Principal of the Leaves of Dwarf Elder (Sambucus ebulus L.) Journal of Ethnopharmacology, Vol. 133, pp. 704-709.

Shibata, S. (2001). Chemistry and Cancer Preventing Activities of Ginseng Saponins and Some Related Triterpenoid Compounds. Journal of Korean Medical Sciences, Vol. 16, pp. 28-37, ISSN 1011-8934.

Shiobara, Y.; Asakawa, Y.; Kodama, M. \& Takemoto, T. (1986). Zedoarol, 13Hydroxygermacrone and Curzeone, Three Sesquiterpenoids from Curcuma zedoaria. Phytochemistry, Vol. 25, pp. 1351-1353.

Singh, A.P.; Wilson, T.; Kalk, A.J.; Cheong, J. \& Vorsa, N. (2009). Isolation of Specific Cranberry Flavonoids for Biological Activity Assesment. Food Chemistry, Vol. 116, pp. 963-968.

Soleas, G.J.; Diamandis, E.P. \& Goldberg, D.M. (1997). Resveratrol: A molecule Whose Time Has Come? And Gone?. Clinical Biochemistry, Vol. 30, pp. 91-113.

Sözer, U.; Dönmez, A.A. \& Meriçli, A.H. (2006). Constituents from the Leaves of Crataegus davisii Browicz. Scientia Pharmaceutica, Vol. 74, pp. 203-208. 
Subbiah, V. (1999). Method Of Isolating Cucurbitacin.United States Patent. 1999, patent number: 5,925,356.

Sur, S.V. (1991). Isolation of Oxygen-Containing Monoterpenoids of Essential Oils by Preparative Adsorbtion Chromatography with Gradient Elution. Khimiya Prirodnykh Soedinenii, Vol. 5, pp. 634-637.

Svedström, U.; Vuorela, H.; Kostiainen, R.; Tuominen, J.; Kokkonen, J.; Rauha, J.P.; Laakso, I. \& Hiltunen, R. (2002). Isolation and Identification of Oligomeric Procyanidins from Crataegus Leaves and Flowers. Phytochemistry, Vol. 60, pp. 821-825.

Syu, W.J.; Shen, C.C.; Don, M.J.; Ou, J.C.; Lee, G.H. \& Sun, C.M. (1998). Cytotoxicity of Curcuminoids and Some Novel Compounds from Curcuma zedoaria. Journal of Natural Products, Vol. 61, pp. 1531-1534.

Tiuman, T.S.; Ueda-Nakamura, T.; Garcia Cortez, D.A.; Dias Filho, B.D.; Morgado-Diaz, J.A.; Souza W. \& Nakamura, C.V. (2005). Antileishmanial Activity of Parthenolide, a Sesquiterpene Lactone Isolated from Tanacetum parthenium. Antimicrobial Agents and Chemotherapy, Vol. 49, pp. 176-182.

Umlauf, D.; Zapp, J.; Becker, H. \& Adam, K.P. (2004). Biosynthesis of the Irregular Monoterpene Artemisia Ketone, the Sesquiterpene Germacrene D and Other Isoprenoids in Tanacetum vulgare L. (Asteraceae). Phytochemistry, Vol. 65, pp. 24632470 .

Vortherms, T.A. \& Roth BL. Salvinorin A: From natural Product to Human Therapeutics. Molecular Interventions 2006 Oct;6(5):257-65.

Wall, M.E. \& Wani, M.C. (1996). Camptothecin and Taxol: From Discovery to Clinic. Journal of Ethnopharmacology, Vol. 51, pp. 239-254.

Wang, G., Tang, W. \& Bidigare, R.R. In Ed: Zhang L., \& Demain, A.L., (2005). Natural Products Drug Discovery and Therapeutic Medicine Terpenoids As Therapeutic Drugs As Pharmaceutical Agents. Humana Press, New Jersey, United States of Amerika.

Watanabe, K.; Mimaki, Y.; Sakagami, H.; \& Sashida, Y. (2002). Cycloartane Glycosides from the Rhizomes of Cimicifuga racemosa and Their Cytotoxic Activities. Chemical Pharmaceutical Bulletin, Vol. 50, pp. 121-125.

Yamada, K.; Murata, T.; Kobayashi, K.; Miyase, T.; \& Yoshizaki, F. (2010). A Lipase Inhibitor Monoterpene and Monoterpene Glycosides from Monarda punctata. Phytochemistry, Vol. 71, pp. 1884-1891. 


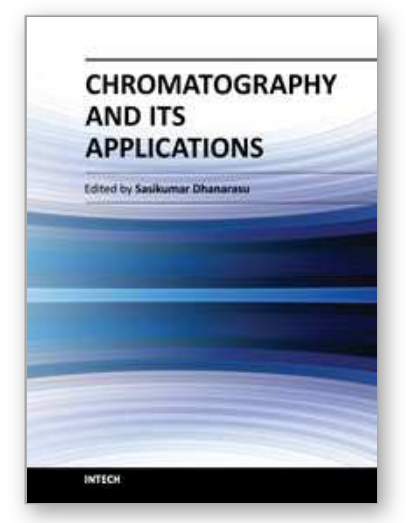

\author{
Chromatography and Its Applications \\ Edited by Dr. Sasikumar Dhanarasu
}

ISBN 978-953-51-0357-8

Hard cover, 224 pages

Publisher InTech

Published online 16, March, 2012

Published in print edition March, 2012

Chromatography is a powerful separation tool that is used in all branches of science, and is often the only means of separating components from complex mixtures. The Russian botanist Mikhail Tswett coined the term chromatography in 1906. The first analytical use of chromatography was described by James and Martin in 1952 , for the use of gas chromatography for the analysis of fatty acid mixtures. A wide range of chromatographic procedures makes use of differences in size, binding affinities, charge, and other properties. Many types of chromatography have been developed. These include Column chromatography, High performance liquid chromatography (HPLC), Gas chromatography, Size exclusion chromatography, Ion exchange chromatography etc. In this book contains more details about the applications of chromatography by various research findings. Each and every topics of this book have included lists of references at the end to provide students and researchers with starting points for independent chromatography explorations. I welcome comments, criticisms, and suggestions from students, faculty and researchers.

\title{
How to reference
}

In order to correctly reference this scholarly work, feel free to copy and paste the following:

Gülçin Saltan Çitoğlu and Özlem Bahadır Acıkara (2012). Column Chromatography for Terpenoids and Flavonoids, Chromatography and Its Applications, Dr. Sasikumar Dhanarasu (Ed.), ISBN: 978-953-51-0357-8, InTech, Available from: http://www.intechopen.com/books/chromatography-and-its-applications/columnchromatography-of-terpenoids-and-flavonoids

\section{INTECH}

open science | open minds

\section{InTech Europe}

University Campus STeP Ri

Slavka Krautzeka 83/A

51000 Rijeka, Croatia

Phone: +385 (51) 770447

Fax: +385 (51) 686166

www.intechopen.com

\section{InTech China}

Unit 405, Office Block, Hotel Equatorial Shanghai

No.65, Yan An Road (West), Shanghai, 200040, China

中国上海市延安西路 65 号上海国际贵都大饭店办公楼 405 单元

Phone: +86-21-62489820

Fax: $+86-21-62489821$ 
(C) 2012 The Author(s). Licensee IntechOpen. This is an open access article distributed under the terms of the Creative Commons Attribution 3.0 License, which permits unrestricted use, distribution, and reproduction in any medium, provided the original work is properly cited. 